Document downloaded from:

http://hdl.handle.net/10251/143132

This paper must be cited as:

Macian Martinez, V.; Serrano, J.; Piqueras, P.; Sanchis-Pacheco, EJ. (15-0). Internal pore diffusion and adsorption impact on the soot oxidation in wall-flow particulate filters. Energy. 179:407-421. https://doi.org/10.1016/j.energy.2019.04.200

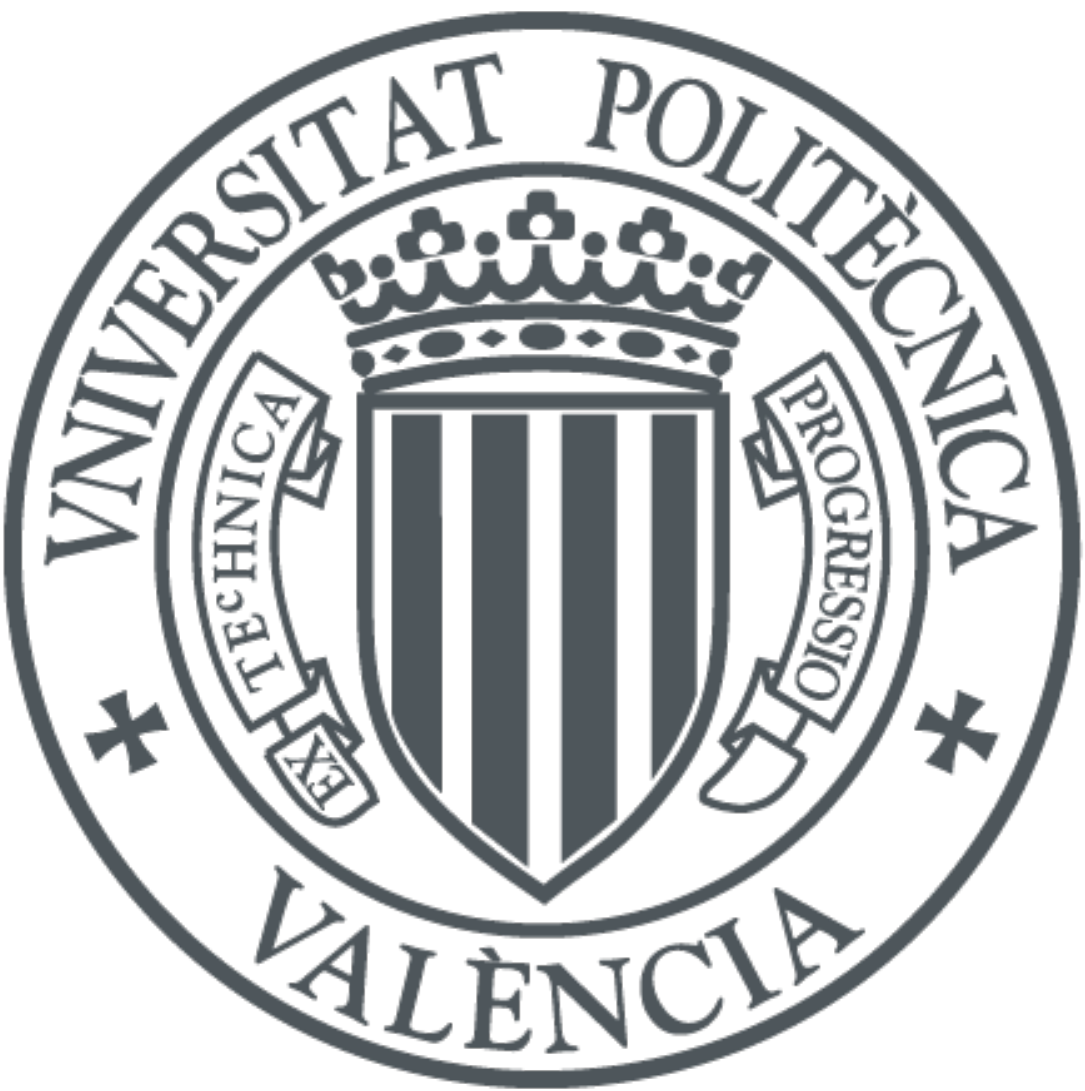

The final publication is available at

https://doi.org/10.1016/j.energy.2019.04.200

Copyright Elsevier

Additional Information 


\title{
Internal pore diffusion and adsorption impact on the soot oxidation in wall-flow particulate filters
}

\author{
V. Macián, J. R. Serrano, P. Piqueras*, E. J. Sanchis* \\ CMT-Motores Térmicos, Universitat Politècnica de València, Camino de Vera s/n, 46022 Valencia, Spain.
}

\begin{abstract}
The automotive industry is driven its efforts to cleaner internal combustion engines. As a result, the engine has become conditioned by the exhaust aftertreatment systems. The regeneration of wall-flow particulate filters (PFs) evidences such an interaction. The PFs prevent the soot emission whereas, as a counterpart, the fuel consumption increases. Consequently, passive and active regeneration strategies are needed to clean the filter back and limit the penalty in $\mathrm{CO}_{2}$. In this context, modelling tools play a key role to achieve a comprehensive understanding and control of the regeneration. In this work, a regeneration model coupled to a one-dimensional compressible unsteady flow solver for PFs is presented. The importance of the main physical and chemical steps related to the soot oxidation is discussed. The influence of the diffusion of gaseous reactants inside the primary soot particles is firstly addressed. The inclusion of this step into the definition of the reaction rate provides temperature dependence to the soot specific surface. Next, the reactants adsorption is analysed. This step leads to define a surface coverage, which behave as an equivalent reaction order. It allows figuring out the influence of the gaseous reactants concentration on the reaction rate and its dependence with the temperature.
\end{abstract}

Keywords: Internal combustion engine, exhaust aftertreatment system, particulate filter, regeneration, soot, modelling

\section{Introduction}

In the last decades, internal combustion engines have undergone an intensive progress in emission control. Despite improvements in the traditional engine processes, such as injection [1], combustion [2] or air management [3], the current and future regulations on pollutant emissions have led to the need of exhaust gas aftertreatment systems (EATS) as key elements for their fulfilment [4]. In the case of particulate matter emissions, wall-flow particulate filters (PFs) are generalised in Diesel engines for more than a decade [5] at the same time as worldwide particulate number tightening regulation trend is also imposing their use in the new generation of gasoline engines [4].

${ }^{*}$ Corresponding author. Tel.: +34 96 3877650, fax: +34 963877659 .

Email address: pedpicab@mot .upv.es (P. Piqueras) 
The accumulation of soot into the PF gives as a result the variation of the porous medium [6] and channels geometric properties [7]. The resulting increase in pressure drop leads to a non-negligible impact on the engine fuel consumption [8] and emissions [9]. Despite the fact that an optimised design in terms of geometry [10] and substrate materials [11] can contribute to reduce the penalty on the engine performance, the periodic filter regeneration, i.e. the oxidation of the collected soot, is required in order to keep the PF pressure drop at low level during engine operation [12]. The minimum temperature for soot oxidation in the presence of $\mathrm{O}_{2}$ is in the range of 500-600 ${ }^{\circ} \mathrm{C}$ [13]. This order of magnitude is over the typical exhaust gas temperature in Diesel engines. Therefore, different active regeneration strategies must be approached [14]. Complementary, continuous passive regeneration is based on the ability of $\mathrm{NO}_{2}$ to oxidise soot above $300^{\circ} \mathrm{C}$ [15]. During normal engine operation, $\mathrm{NO}_{2}$ assisted regeneration is promoted increasing the $\mathrm{NO}_{2}$ concentration at the wall-flow diesel particulate filter (DPF) inlet by oxidising NO in a previous oxidation catalyst [16]. Additionally, the DPF can be catalysed with a platinum coating as a way to enhance the $\mathrm{NO}$ to $\mathrm{NO}_{2}$ oxidation across the inlet channels of the wall-flow monolith [17]. Another common passive regeneration strategy consists of the use of metal oxides, such as $\mathrm{CeO}_{2}$, as additives during the engine combustion process. These metal oxides promote the formation of surface nitrates which favour both $\mathrm{O}_{2}$ and $\mathrm{NO}_{2}$ soot oxidation [18].

The regeneration modelling shows great dependence on the thermo-and fluid-dynamic field of the filter [19] as well as on the soot reactivity [20]. The work of Bisset [21] stands out among the first studies on the mathematical modelling of the regeneration process in wall-flow particulate filters. The work was focused on the thermal regeneration of particle filters in the presence of $\mathrm{O}_{2}$. The proposed mathematical model solves the conservation of mass, momentum and energy in a single pair of inlet and outlet channels coupled by the flow across the porous medium.

Although the Bisset's model assumes the complete oxidation of soot, later experimental studies evidenced that a non-negligible amount of CO is produced during the regeneration [22]. Hence, an index of soot oxidation completeness [23] was included to account for the incomplete soot oxidation in the presence of $\mathrm{O}_{2}$. In a similar way, Koltsakis et al. [24] also defined the corresponding $\mathrm{NO}_{2}$ index of completeness as way to properly deal with the modelling of passive regeneration.

Besides incomplete oxidation, the basis of solid carbon oxidation postulates a series of steps previous and subsequent to the formation of the oxidation products. Among these steps, the main limiting ones are the diffusion of the gaseous reactants from the external to the internal pores, the adsorption of the reactants on the soot surface, which gives rise to the reaction intermediate products, and their final rearrangement to form the oxidation products [25]. Other steps concerning the products, such as their desorption, have lower impact on the overall reaction rate since their characteristic velocity is several orders of magnitude higher than the one corresponding to the reactants related steps [26].

Although the internal pore diffusion is not traditionally taken into account to describe the regeneration process, the diffusion of the reactants inside the pores of carbon particles was already discussed in the early 80's by Smith [27], who proposed a classification of the oxidation reactions as a function of the degree of penetration of the oxidising species into the pores of a coal particle. Concerning $\mathrm{O}_{2}$ interaction with diesel soot particles, Kandas et al. [28] 
analysed the evolution of the surface area of various soot samples during their oxidation applying small angle X-ray scattering and $\mathrm{CO}_{2}$ adsorption techniques. The results showed simultaneous variation of the size and internal structure of the particles. It suggested a dual oxidation process, i.e. both internal and external burning out. Song et al. [29] applied transmission electron microscopy to analyse the microstructure of soot primary particles generated by several diesel fuels at different stages of oxidation. The oxidation was also shown to vary the internal structure of biodiesel soot particles along the burn out process. The penetration of $\mathrm{NO}_{2}$ into the soot particles derived from combustion has been also discussed by Tighe [30]. Shrinking and dual combustion models were applied to fit the reaction rates coming from thermogravimetric analysis. Similar accuracy was provided by both approaches, despite the fact that $\mathrm{NO}_{2}$ evidenced diffusion into the particles internal pores. Although the diffusion mechanism was concluded not to control the oxidation process, this statement was based on the computation of the $\mathrm{NO}_{2}$ molecular diffusivity and the comparison of the diffusion rate with respect to the kinetic constant. However, the use of molecular diffusivity contrasts with the representative diameter of the soot internal pores [31], which falls into the configurational diffusion regime [32].

On the other hand, the kinetic model suitable to represent the complex mechanism of the carbon particles oxidation has been generally discussed applying an indirect approach based on the reaction order of the oxidising species [33]. The most extended solution assumes first-order kinetics to describe the complete reaction mechanism as a single step, as done by Ghiassi et al. for carbon black [34], by Guo et al. for diesel soot [35] and Rodriguez-Fernández et al. for dry soot (devolatised diesel soot) [36]. However, the assumption of a kinetics of non-integer order covering the range 0.5 [37] to 0.94 [38] is also commonly found in the literature. In this regard, there are multiple experimental and theoretical data that point out the gaseous reactants adsorption on the surface of the carbon particle prior to the formation of the reaction products [39]. In order to consider the influence of the adsorption step on the overall reaction kinetics, the adsorption isotherms provide a more solid approximation than calibrated non-integer Arrhenius expressions [40]. This approach was applied by Essenhigh [41], who proposed to describe the adsorption process by the Langmuir isotherm. More recently, Messerer et al. [42] combined the Langmuir isotherm and the Arrhenius equation to model diesel soot oxidation in the presence of $\mathrm{NO}_{2}$ keeping just the Arrhenius equation for $\mathrm{O}_{2}$ because of the low temperature and its lack of impact on the tested oxidation processes.

Due to the evidences stressing the importance of the reactants internal pore diffusion and adsorption, this paper proposes a wall-flow particulate filter regeneration model that includes these phenomena in the definition of the reaction rate term. The model is integrated into a one-dimensional (1D) unsteady compressible non-homentropic flow solver [43]. This way, the regeneration is not evaluated assuming the soot oxidation as an standalone process but conditioned by the thermo-and fluid-dynamic field. The model capability to describe the soot oxidation dynamics is contrasted comparing against experimental data corresponding to DPF passive and active regeneration tests. Finally, a parametric study is conducted as a function of the temperature, mass flow and reactants concentration to reach further understanding on the impact of the internal pore diffusion and adsorption on the reaction rate. 


\section{Regeneration model}

The proposed regeneration model is implemented into an integral thermo-and fluid-dynamic solver [43] for wallflow particulate filters, which accounts for pressure drop [44], heat transfer [45] and filtration [46] modelling. As detailed in the Appendix, the model solves the governing equations assuming one-dimensional unsteady compressible non-homentropic flow. The filter regeneration affects the flow transport in different ways. On the one hand, the soot oxidation produces a decrease in the amount of soot accumulated within the porous medium. This parameter directly affects the pressure drop [44] and can vary the filtration efficiency as a function of the soot mass load [46]. In addition, the heat released by the soot oxidation increases the substrate temperature [45]. On the other hand, the regeneration model determines the gas composition at the porous wall outlet, which defines the source term of the chemical species conservation equation in the outlet channel, as shown in the Appendix.

Figure 1 shows an scheme of the channels discretisation in the axial direction and the cross-section of an inlet channel, where the main geometrical characteristics of the cell are identified. The gas composition entering the outlet channel in every axial node is obtained solving the conservation equation of chemical species across the porous medium, i.e. in the tangential direction. Therefore, its coupling with the flow solver defines a 1D+1D regeneration model. In particular, the conservation equation of the gaseous reactants is solved along three different layers composing the porous medium. These layers are the particulate layer, which is a region of variable thickness as a function the amount of accumulated soot; the loaded porous wall, which is a region of the porous wall of constant thickness where soot is collected; and the non-loaded porous wall [46], where neither soot accumulation nor reaction takes place.

The gaseous reactants considered in this work are $\mathrm{O}_{2}$ and $\mathrm{NO}_{2}$, as shown in Eqs (1) and (2),

$$
\begin{gathered}
\mathrm{C}+\alpha_{\mathrm{O}_{2}} \mathrm{O}_{2} \rightarrow 2\left(\alpha_{\mathrm{O}_{2}}-0.5\right) \mathrm{CO}_{2}+2\left(1-\alpha_{\mathrm{O}_{2}}\right) \mathrm{CO} \\
\mathrm{C}+\alpha_{\mathrm{NO}_{2}} \mathrm{NO}_{2} \rightarrow \alpha_{\mathrm{NO}_{2}} \mathrm{NO}+\left(2-\alpha_{\mathrm{NO}_{2}}\right) \mathrm{CO}+\left(\alpha_{\mathrm{NO}_{2}}-1\right) \mathrm{CO}_{2}
\end{gathered}
$$

which account for the index of oxidation completeness for $\mathrm{O}_{2}$ and $\mathrm{NO}_{2}$ species according to the model proposed by Zeng et al. [47] and the calibration from Jeguirim et al. [48].

The regeneration is assumed to be a quasi-steady process with negligible impact of the diffusive transport across the porous medium. This hypothesis is discussed to be valid in controlled regenerations and no $\mathrm{NO}_{2}$ promotion into the porous wall [49]. Therefore, Eq. (3) represents the convective transport equation to be applied across every layer of the porous medium,

$$
\frac{\partial\left(\rho u_{w} A_{f} Y_{n}\right)}{\partial z}=\rho A_{f} \frac{M_{n}}{\bar{M}} \dot{\omega}_{n}
$$

where $u_{w}$ and $A_{f}$ are the filtration velocity and area respectively and $\rho$ represents the gas density. $Y_{n}$ identifies the mass fraction of the gaseous reactant $n$, i.e. $\mathrm{O}_{2}$ or $\mathrm{NO}_{2}$. Taking into account that $M_{n}$ and $\bar{M}$ are the molar mass of 
the reactant $n$ and the gas mixture respectively, assuming incompressible flow and constant filtration velocity and area across every layer, Eq. (3) can be rewritten in molar fraction terms $\left(X_{n}\right)$ as

$$
u_{w} \frac{\partial X_{n}}{\partial z}=\dot{\omega}_{n}
$$

where the term $\dot{\omega}_{n}$ represents the reaction rate of the reactant $n$, which is defined in a general way as:

$$
\dot{\omega}_{n}=-f\left(S_{p}, \eta_{i n t_{n}}\right) \alpha_{n} k_{n} f\left(p_{n}, T_{w}\right)
$$

Eq. (5) accounts for the main solid-to-gas steps that can limit the effective reaction rate, as sketched in Figure 2. In Eq. (5), $\alpha_{n}$ is the completeness index of the reactant $n ; f\left(S_{p}, \eta_{i n t_{n}}\right)$ is a function of the soot specific surface $\left(S_{p}\right)$ and the internal pore diffusion of the reactant $n\left(\eta_{i n t_{n}}\right)$. This last term is in turn a function of microstructural soot properties, substrate temperature, reactant concentration and kinetic parameters, as forward discussed in Section 2.2. The kinetic constant of the soot oxidation against the reactant $n\left(k_{n}\right)$ is calculated according to the Arrhenius equation as a function of the substrate temperature. Finally, the function $f\left(p_{n}, T_{w}\right)$ represents the reaction dependence on the reactant partial pressure $\left(p_{n}\right)$, i.e. the reactant concentration and absolute pressure dependence, and the substrate temperature $\left(T_{w}\right)$. It is modelled according to the Langmuir isotherm, as described in Section 2.1.

\subsection{Adsorption process}

The surface concentration of the gaseous reactants is determined from their gas flow concentration by means of the Langmuir isotherm. This adsorption isotherm has been successfully applied in previous works to calculate the surface concentration of both $\mathrm{O}_{2}[50]$ and $\mathrm{NO}_{2}$ [42] when modelling the oxidation of carbon particulates in chemical reactors.

The general expression of the Langmuir isotherm, which substitutes the term $f\left(p_{n}, T_{w}\right)$ in Eq. (5), is

$$
\theta_{n}=\frac{K_{S_{n}} p_{n}}{1+K_{S_{n}} p_{n}},
$$

where the term $K_{S_{n}}$ represents the adsorption equilibrium constant of the reactant $n$ according to Eq. (7). The values of the adsorption enthalpy $\left(\Delta H_{S_{n}}\right)$, which is defined as the adsorption to desorption activation energy difference, and the pre-exponential factor $\left(A_{S_{n}}\right)$ are detailed in Table 1.

$$
\left.\begin{array}{l}
k_{a d s_{n}}=A e^{-\frac{E_{a d s_{n}}}{\Re T_{w}}} \\
k_{d s_{n}}=B e^{-\frac{E_{a_{d e s}}}{\Re T_{w}}}
\end{array}\right\} K_{S_{n}}=\frac{A}{B} e^{-\frac{E_{a_{a d s_{n}}-E_{a_{d e s}}} T_{w_{w}}}{T_{w}}}=A_{S_{n}} e^{-\frac{\Delta H_{S_{n}}}{\Re T_{w}}}
$$

\subsection{Internal pore diffusion}

The dependence of the soot oxidation on the particles geometry has been widely discussed. The most common approach assumes an oxidation shrinking core mechanism. This is the case of the work performed by Jung et al. [54], who visualised the combustion of acetylene soot concluding its impermeability to $\mathrm{O}_{2}$. In contrast, other authors, 
as Ghiassi et al. [34], highlight the importance of the particles microstructure and its impact on the internal pore diffusion for the correct determination of the reaction rate. This dual combustion approach, i.e. external and internal soot particle oxidation, finds support in the study presented by Song et al. [29]. The variation of the microstructure of the bio-diesel soot was analysed during the oxidation process. Although the combustion was initially observed to take place on the soot external surface, most of the reaction was demonstrated to occur internally after the removal of the soluble organic fraction (SOF) adsorpted inside the micro-pores.

These observations are consistent with previous studies focused on the analysis of the soot specific surface variation as the oxidation takes place. Ishiguro et al. [55] showed an increase of the surface area as the combustion is completed. The increase in surface area was demonstrated to be higher than the one corresponding to an external combustion with particle diameter reduction. Therefore, the high magnitude of the surface area increase was attributed to changes in the internal particle microstructure. On the other hand, Kandas et al. [28] found an increase in surface area after the removal of volatile matter. Such variation was related to internal micro-pores, which became accessible to gas molecules.

The possibility to distinguish between external and internal specific surface makes possible to apply these concepts to the regeneration modelling. In the present work, the mass based soot specific surfaces for diesel soot provided by Kandas et al. [28] are considered. The external mass based specific surface is $96 \mathrm{~m}^{2} / \mathrm{g}$. This value is similar to that provided by other authors, such as Tighe [56] and Jaramillo [57]. The difference between the external specific surface and the value provided after SOF removal ( $367 \mathrm{~m}^{2} / \mathrm{g}$ [28]), which coincides in range with the one provided by Lapuerta et al. [58], is used as internal mass based specific surface. These values are similar to those obtained in [55] once the oxidation process is initiated. Since the specific surface in Eq. (5) is defined in volumetric terms, the soot density in every region has been applied to determine the volumetric based specific surfaces. The soot density in the particulate layer has been imposed to $700 \mathrm{~kg} / \mathrm{m}^{3}$, which is obtained from the particulate layer porosity determination carried out in previous studies [59]. The density of the soot within the porous wall is taken as the representative density of the soot aggregates with mean fractal dimension and number of primary particles $\left(345 \mathrm{~kg} / \mathrm{m}^{3}\right)$ [60]. In both cases, the carbon density has been assumed to be $2000 \mathrm{~kg} / \mathrm{m}^{3}$. The resulting volume based soot specific surfaces are shown in Table 2. It is relevant to note that the external specific surfaces are in the same order of magnitude as the specific surface used in classic regeneration models, such as the Bisset [61] and Koltsakis [23] proposals.

Despite the ability to distinguish between external and internal soot specific surface, the impact of the soot microstructure variation during the regeneration on the reactivity has been assumed negligible. On the one hand, the soot collected into the monolith is free of volatile compounds since, as in this work, the DPF is usually preceded by an oxidation catalyst [62], being one of its functions the oxidation of the SOF trapped in the soot particles [63]. On the other hand, this hypothesis is supported by the experimental results provided by Kandas et al. [28], who evidenced that the variation in specific surface was almost negligible once the SOF was removed.

Therefore, the reaction rate term shown in Eq. (5) can be rewritten as 


$$
\dot{\omega}_{n}=-\underbrace{\left(S_{p, \text { ext }}+\eta_{\text {int }} S_{p, \text { int }}\right)}_{\text {Effective specific surface }} \alpha_{n} k_{n} f\left(X_{n}, T_{w}\right),
$$

where the internal pore diffusion efficiency times the internal soot specific surface defines the effective internal soot specific surface. The internal pore diffusion efficiency is computed as a function of the Thiele modulus [64] applied to a soot primary particle:

$$
\eta_{\text {int }}=\frac{1}{\phi_{n}}\left(\frac{1}{\tanh \left(3 \phi_{n}\right)}-\frac{1}{3 \phi_{n}}\right)
$$

Since the kinetic mechanism includes an adsorption step, the Thiele modulus for spherical particles is calculated as proposed by Hong et al. [65] referred to the internal specific surface of the soot particles:

$$
\phi_{n}=\frac{d_{\text {part }, p}}{6} \sqrt{\frac{S_{p, \text { int }} k_{n} \alpha_{n}}{2 D_{c, n}\left(K_{S_{n}} p_{n}-\log \left(1+K_{S_{n}} p_{n}\right)\right)}} \frac{K_{S_{n}} p_{n}}{1+K_{S_{n}} p_{n}}
$$

The term $d_{\text {part,p }}$ defines the diameter of the soot primary particle. Its value and other soot properties used in this work are shown in Table 2. The pore radius $\left(r_{p, s}\right)$ is the mode of the pore size distribution of a virtual carbon particle, as described by Biggs and Buts [31]. From this order of magnitude it is possible to conclude that the internal pore diffusion falls into the configurational diffusion regime. The diffusivity due to this mechanism is calculated applying the Salatino's procedure [66]:

$$
D_{c, n}=D_{k, n} e^{-\frac{E_{a d s_{n}}}{\mathfrak{R} T_{w}}}
$$

In Eq. (11), $E_{a_{a d s n}}$ represents the adsorption activation energy of the reactant $n$. It has been determined as a function of the substrate temperature taking into account the results from different studies with $\mathrm{O}_{2}$, as shown in Figure 3. Since $\mathrm{O}_{2}$ and $\mathrm{NO}_{2}$ have similar adsorption enthalpy (Table 1), the same activation energy has been assumed for both gaseous reactants. In addition, the calculation of the molecular diffusivity requires the Knudsen diffusivity $\left(D_{k, n}\right)$, which is defined as [67]:

$$
D_{k, n}=\frac{2 r_{p, s}}{3} \sqrt{\frac{8 \Re T_{w}}{\pi M_{n}}}
$$

\subsection{Solution of the chemical species transport in the porous medium}

From the description of the internal pore diffusion and adsorption steps, the reactant species conservation equation across the porous medium can be finally written as:

$$
u_{w} \frac{\partial X_{n}}{\partial z}=-\left(S_{p, e x t}+\eta_{i n t_{n}} S_{p, i n t}\right) \alpha_{n} k_{n} \frac{K_{S_{n}} p_{n}}{1+K_{S_{n}} p_{n}}
$$

Eq. (13) is solved for $\mathrm{O}_{2}$ and $\mathrm{NO}_{2}$ applying a $4^{\text {th }}$-order Runge-Kutta method consecutively to every layer, which are solved in a decoupled way. It makes necessary to impose the concentration at the inlet of every region as a 
boundary condition. In the case of the region in the interface with the inlet channel, the concentration is imposed as that of the species in the inlet channel gas flow because of the convective transport across the porous medium. The concentration of the species at the outlet of every layer are then imposed as the boundary condition for the solution of the next one.

The gas composition at the outlet section is determined as a function of the inlet mass fraction for every species and the variation in mass fraction of reactants and products. In particular, the soot mass fraction variation in the gas stream is obtained by solving the filtration process [46] whereas the variation of the products mass fraction is obtained by stoichiometry according to Eqs. (1) and (2),

$$
\Delta Y_{p}=-\frac{M_{p}}{\bar{M}} \sum_{n} v_{p, n} \Delta X_{n}
$$

where $M_{p}$ and $\bar{M}$ are the molar masses of the product $p$ and the gas mixture, respectively; $v_{p, n}$ is the stoichiometric coefficient of the product $p$ generated in the soot oxidation against the reactant $n$ and $\Delta X_{n}$ represents the molar fraction variation of the gaseous reactant leading to product $p$ formation. Consequently, the outlet mass fraction of the chemical species $m$ is given by:

$$
Y_{m, w_{\text {out }}}=\frac{\dot{m}_{m, w_{\text {out }}}}{\dot{m}_{w_{\text {out }}}}=\frac{Y_{m, w_{\text {in }}}+\Delta Y_{m}}{1+\sum \Delta Y_{k}}
$$

In Eq. (15), $\dot{m}_{m, w_{\text {out }}}$ and $\dot{m}_{w_{\text {out }}}$ represent the mass flow of the species $m$ and the total mass flow at the porous medium outlet of every node respectively.

The amount of oxidised soot mass $\left(m_{s, r e g}\right)$ and the heat released per unit of time $\left(\dot{q}_{r e g}\right)$ in every layer is determined from the depletion rate of the gaseous reactants and the heat of formation of the involved chemical species,

$$
\begin{gathered}
\frac{\partial m_{s, r e g}}{\partial t}=M_{C}\left(-\frac{1}{\alpha_{\mathrm{NO}_{2}}} \frac{\partial n_{\mathrm{NO}_{2}}}{\partial t}-\frac{1}{\alpha_{O_{2}}} \frac{\partial n_{\mathrm{O}_{2}}}{\partial t}\right), \\
\dot{q}_{r e g}=\sum_{n} \dot{q}_{r e g, n}=\sum_{n} \sum_{k} \frac{v_{k, n}}{\alpha_{n}} H_{f, k} \frac{\partial n_{n}}{\partial t}
\end{gathered}
$$

being $H_{f, k}$ the enthalpy of formation of the species $k$. The depletion rate of the reactant $n$ in every node of the porous medium is obtained from the variation in molar fraction provided by the solution of Eq. (13) according to

$$
\frac{\partial n_{n}}{\partial t}=\Delta X_{n} u_{w} A_{f} c_{g a s}
$$

where $c_{g a s}$ is the gas flow molar concentration.

\section{Experimental setup and tests}

The performance of the proposed PF regeneration model is discussed taking as baseline several DPF regenerations carried out in an engine test bench. All the modelled tests were performed in a wall-flow DPF whose characteristics 
are summarised in Table 3. The details of the experimental setup, which is sketched in Figure 4, can be found in [71]. In particular, a Euro 4 Diesel engine, whose main characteristics are shown in Table 4, was used. The monitoring of the aftertreatment operating conditions covered the measurement of the air and fuel mass flow by a sensy-flow and a gravimetric balance, respectively; the DPF pressure drop by placing two piezorresistive transducers at the inlet and outlet cones of the DPF; and the inlet and outlet temperature with K-type thermocouples placed in the inlet and outlet DPF canning cones.

The exhaust gaseous emissions were measured by an Horiba Mexa 6000 F-TIR analyser placed downstream of the DPF. The particle concentration and size distribution were also measured by using a TSI Engine Exhaust Particle Sampler following the methodology proposed by Desantes et al. [72]. Additionally, a by-pass system with two electrovalves was placed upstream of the aftertreatment system to provide higher control on the DPF soot mass load at the beginning of every test. During the engine stabilisation the valve in the aftertreatment branch was completely closed and the by-pass valve controlled the tailpipe exhaust pressure. Once the engine was stabilised in the target operating point, the by-pass path was closed forcing the exhaust gas mass flow across the DPF.

Three regeneration processes have been considered in this work. They consist of a loading process subjected to passive regeneration and two active regeneration processes with different initial soot mass load $(11 \mathrm{~g} / 1$ and $22 \mathrm{~g} / \mathrm{l})$. As a first step before every soot loading, the DPF was weighed in clean conditions right after a previous regeneration. Once the loading tests were completed, the DPF was weighed in hot conditions to avoid the influence of the porous medium hygroscopic nature [73]. All the loading tests were performed under steady-state conditions at $2500 \mathrm{rpm}$, $28 \%$ in engine load and SR-EGR rate of $16 \%$. After weighing the DPF to verify the soot load, an active strategy based on fuel post-injection was applied to regenerate the DPF back to clean conditions with 0.08 in $\mathrm{O}_{2}$ molar fraction.

\section{Results and discussion}

\subsection{Experimental validation}

The modelling of the regeneration tests has been carried out taking as boundary conditions the exhaust gas mass flow, the inlet gas temperature and the outlet gas pressure under the assumption of homogenous soot mass distribution within the monolith. The model calibration is based on methodologies discussed separately in previous works concerning pressure drop under clean [74] and soot loaded conditions [44], filtration [46] and heat transfer [45]. With this baseline, Table 5 shows the pre-exponential factors and the activation energy to calculate the Arrhenius kinetic constants for $\mathrm{O}_{2}$ and $\mathrm{NO}_{2}$. These define the soot depletion rate that fits the pressure drop and the outlet gas temperature and were used for the modelling of all the regeneration cases. Due to the impact of every reactant as a function of the type of tests, the constants for $\mathrm{O}_{2}$ were determined from the active regeneration tests whilst the $\mathrm{NO}_{2}$ kinetic parameters were defined taking as reference the passive regeneration test.

The profiles of the pressure drop and the outlet gas temperature during the active regeneration tests are shown in plots (a) and (b) of Figure 5 respectively. The model shows good ability to reproduce the thermo-and fluid-dynamic 
response of the DPF independently of the initial soot mass load and inlet gas temperature, which determines the differences in soot oxidation dynamics. As expected, a sudden initial increase of the pressure drop takes place. It is due to the temperature increase, which is still not promoting a relevant soot depletion rate. Nevertheless, the soot oxidation takes importance progressively leading to the maximum in pressure drop. An overestimate in pressure drop prediction is found during this stage in the regeneration corresponding to $22 \mathrm{~g} / 1$ in initial soot mass load. In terms of temperature, the effects of the heating-up and soot oxidation initiation stage are shifted towards the regeneration end stage because of the monolith thermal inertia and the dynamics of the soot depletion rate, as forward explained. As a final stage, the pressure drop starts decreasing governed by the gradual reduction in accumulated soot mass and oxidation rate.

This preliminary analysis evidences the existence of three stages along the active regeneration. Despite discussions focused on the comparison of inlet and outlet gas temperature [61], the modelling allows explaining the dynamics of the regeneration process directly by the overall soot depletion rate. Figure 6 unequivocally identifies the different stages based on the overall soot depletion rate, and hence also on the pressure drop derivative, which is experimentally available. The initial preheating stage is characterised by a fast increase of the overall soot depletion rate derivative, as shown in Figure 6(a). It is governed by the inlet gas temperature profile, which determines the soot depletion rate in the proximity of the inlet monolith cross-section. Alternatively, this first stage is also defined by positive pressure drop derivative, as observed in Figure 6(b). Once the pressure drop derivative equals 0 , the maximum reactivity stage starts. This stage is bounded by the maximum to minimum values in overall soot depletion rate derivative. During this second stage, the pressure drop decreasing rate is growing up till a maximum (minimum in pressure drop derivative) that coincides with the inflection point of the overall soot depletion rate derivative. From this point on, the late oxidation stage takes place. This stage is characterised by a progressive smooth that slows down the overall soot depletion rate and the pressure drop decrease, as clearly indicated by the trend in their derivatives.

The fashion in pressure drop dynamics is also related to local properties. Figure 7 shows substrate and flow properties in three different axial monolith locations $(2 \mathrm{~cm}, 10 \mathrm{~cm}$ and $18 \mathrm{~cm})$ for both active regeneration processes. As a reference, the DPF soot mass variation along the regeneration process is represented in Figure 7(a).

A small portion of collected soot $(6 \% \sim 7.5 \%)$ is oxidised during the preheating stage. It coincides with high local soot depletion rate till $2 \mathrm{~cm}$ in monolith length (Figure 7(b)). The soot oxidation in this region slightly affects the particulate layer thickness, as shown in Figure 7(c). However, it has a relevant impact on the porous wall saturation. The sudden step in local soot depletion rate indicates the moment at which the model predicts the complete porous wall regeneration. Consecutive discontinuities in the overall soot depletion rate derivative, which are clearly observed in Figure 6(a), indicate the gradual removal of the soot within the porous wall. These discontinuities appear during the maximum reactivity stage. In fact, their effect is also observed in the pressure drop derivative, both modelled and experimental profiles (Figure 6(b)). In both active regeneration tests, the second stage covers the maximum values in local soot depletion rate from $2 \mathrm{~cm}$ on. This stage is the shortest one, with an approximate duration of $50 \mathrm{~s}$ and a soot mass depletion close to $\sim 26 \%$. At the end of this stage the particulate layer thickness has clearly decreased till 
$10 \mathrm{~cm}$, what leads to a quasi-steady value of the filtration velocity. However, the particulate layer thickness is scarcely affected in the rear end region of the inlet channels. It makes most of the flow be driven across the less loaded inlet channel region during the late oxidation stage. Consequently, the filtration velocity in the rear end increases slowly. The limited amount of reactant mass flow gives as a result the lowest $\mathrm{O}_{2}$ concentration across the porous medium, in particular at the porous wall outlet (Figure 7(e)).

Figure 8 shows the progress of the substrate temperature at different monolith cross-sections. The heat released by the soot oxidation causes an increasing temperature front that moves forwards. As a consequence, the maximum temperature is reached at the monolith rear end. Besides the soot depletion rate, the maximum temperature peak is also determined by the monolith thermal inertia, which smooths its magnitude and moves it to the late oxidation stage. In fact, the temperature peak is even negligible at medium-low soot loads, as shown in Figure 8(b). The combined effect of reaction rate and thermal inertia modelling provides the accuracy in the prediction of the outlet gas temperature previously represented in Figure 5(b).

The model validation is completed with the simulation of a soot loading test up to $11 \mathrm{~g} / \mathrm{l}(30 \mathrm{~g})$. This process demands a coupled computation of filtration [46] and $\mathrm{NO}_{2}$ soot oxidation. The boundary conditions of the test are defined by $220 \mathrm{ppm}$ in NOx concentration at the DPF inlet and a $\mathrm{NO}_{2}$ to $\mathrm{NOx}$ ratio equal to $58 \%$ once the DOC thermal transient is completed. Figure 9 compares the experimental and modelled pressure drop as a function of the soot mass load and time in plots (a) and (b) respectively. The simulation was run with and without regeneration modelling. As expected, Figure 9(a) shows that the DPF pressure drop can be properly captured without regeneration as a function of the soot mass load. This kind of representation reduces the modelling requirements to pressure drop concerns [44]. The properties of the porous medium are estimated with accuracy as a function of the soot mass load being other parameters, such as the change in substrate and gas temperature, of second-order in terms of pressure drop prediction. This is due to the low soot depletion rate, which scarcely affects the temperature field.

Besides the soot mass influence, the pressure drop profile during the passive regeneration can be also analysed with a time-dependent approach. Such a dependence can be only reproduced taking into account both soot collection and oxidation. The last one is in turn controlled by the $\mathrm{NO}_{2}$ reduction being the $\mathrm{O}_{2}$ influence neglected due to the low gas temperature $\left(315^{\circ} \mathrm{C}\right)$. Figure 9 (b) shows almost perfect agreement in pressure drop as a function of time between experimental and modelled results when the regeneration model is applied. These results point out that the instantaneous prediction of accumulated soot mass within the monolith as well as the porous medium properties are correct as a consequence of the combined filtration and soot oxidation modelling.

As additional insight, the correct modelling of the passive regeneration process is also conditioned by the prediction of the $\mathrm{NO}_{2}$ and $\mathrm{NO}$ molar concentration at the DPF outlet. Its variation along the soot loading test is represented in Figure 10. The model captured the dynamics of the passive soot oxidation with good accuracy regarding both soot oxidation onset, which takes place at time $\sim 1500 \mathrm{~s}$, and tailpipe NOx concentration. According to Eq. (13), the thickness of the particulate layer is the only parameter affecting the reaction rate under steady-state engine operating conditions. Hence, NOx species concentration shows an almost linear variation at the DPF outlet once the soot oxida- 
tion starts. It points out an increasing soot depletion rate, which is directly governed by the growth of the particulate layer thickness.

\subsection{Effect of internal pore diffusion}

As described in Section 2, the limitations in reaction rate caused by the internal pore diffusion step are assessed by means of the diffusion efficiency. This term is governed by the Thiele modulus and sets the effective internal specific surface of soot according to Eq. (13). Figure 11 represents the internal pore diffusion efficiency of $\mathrm{O}_{2}$ and $\mathrm{NO}_{2}$ as a function of the substrate temperature and the reactant concentration.

Despite a minor impact of the molar fraction range corresponding to $\mathrm{O}_{2}$, the internal pore diffusion efficiency can be concluded to be determined by the substrate temperature. According to this dependence, the limitations due to internal pore diffusion can be divided into three different temperature ranges. As a first region, the influence of the internal pore diffusion is assumed negligible below $400^{\circ} \mathrm{C}$ for $\mathrm{O}_{2}$ and $300^{\circ} \mathrm{C}$ for $\mathrm{NO}_{2}$. These ranges almost fall into the range in which these reactants do not promote relevant soot oxidation due to chemical kinetic limitation. As the temperature increases, the efficiency reaches a linear dependence up to $650^{\circ} \mathrm{C}$ for $\mathrm{O}_{2}$ and $550^{\circ} \mathrm{C}$ for $\mathrm{NO}_{2}$. This regime determines a variation in internal pore diffusion efficiency between 0.9 and 0.35 both for $\mathrm{O}_{2}$ and $\mathrm{NO}_{2}$. From these temperatures on, the efficiency reaches an asymptotic behaviour converging to 0.2 for $\mathrm{O}_{2}$ and 0.1 for $\mathrm{NO}_{2}$ at $1000^{\circ} \mathrm{C}$. These results reveal a significant impact on the effective internal specific surface within the temperature range of high reactivity for active $\left(\mathrm{O}_{2}\right)$ and passive $\left(\mathrm{NO}_{2}\right)$ regeneration processes.

Figure 12 shows the influence of the internal pore diffusion efficiency in an active regeneration event. The test corresponds to an initial soot mass load of $11 \mathrm{~g} / \mathrm{l}$. The results obtained by the modelling of the internal pore diffusion are compared against a case with the same kinetic parameters but without pore diffusion step (Setting A) and a refitting of these settings when the pore diffusion step is neglected (Setting B). In these two last cases, both the external and internal soot specific surfaces are considered. The results in plots (a), (b) and (c) in Figure 12, which represent the pressure drop, the outlet gas temperature and the overall soot depletion rate respectively, show that the internal pore diffusion is very relevant for the accuracy of the regeneration dynamics prediction. The comparison of the baseline results (w/ diffusion) against the results from Setting A (w/o diffusion) highlights how the internal pore diffusion step reduces the maximum depletion rate and moves the soot oxidation towards the late oxidation stage. Figure 12(d) shows a minimum internal pore diffusion efficiency around $0.5\left(\sim 600^{\circ} \mathrm{C}\right)$ being its transient variation depending on the local substrate temperature profile. These results lead to a relevant underestimation of both activation energy and pre-exponential factor when the kinetic parameters are re-calibrated for the modelling w/o diffusion, as shown for Setting B in Table 6.

\subsection{Effect of adsorption}

According to the Langmuir isotherm, the adsorption process is dependent on the temperature and the reactant partial pressure. Figure 13 shows the sensitivity against these parameters considering representative ranges for $\mathrm{O}_{2}$ and 
$\mathrm{NO}_{2}$ molar concentration at 1 bar in absolute pressure. Typical low $\mathrm{NO}_{2}$ concentration leads to an almost constant surface coverage over its common light-off temperature $\left(\sim 300^{\circ} \mathrm{C}\right)$. However, the $\mathrm{O}_{2}$ surface coverage shows high sensitivity to the temperature within the regular range of active regeneration as well as a minor dependence on $\mathrm{O}_{2}$ molar fraction, i.e. partial pressure.

These results invite to resort to the concept of reaction order, which is commonly imposed as a constant value in the literature, as discussed in Section 1. According to Eq. (19), the Langmuir surface coverage can be related to an equivalent reaction order as:

$$
n_{e q, n}=\frac{\log \theta_{n}}{\log X_{n}}
$$

Taking into account the results in Figure 13, the $\mathrm{NO}_{2}$ equivalent reaction order ranges $0.3-0.4$ within the represented molar concentration and the typical passive regeneration temperature. The case of $\mathrm{O}_{2}$ is more complex. It is not possible to set a constant representative reaction order for a whole regeneration event. This is mainly because of the temperature sensitivity. The equivalent reaction order as a function of temperature, $\mathrm{O}_{2}$ molar fraction and absolute pressure is represented in Figure 14(a). Two absolute pressures and three molar fractions are considered, thus representing the effect of 6 partial pressure cases. The equivalent reaction order starts to increase from 0 once the temperature is over $350^{\circ} \mathrm{C}$. The initial slope is slightly higher for low concentration cases. Nevertheless, the impact of this parameter can be assumed negligible below $675^{\circ} \mathrm{C}$, when the equivalent reaction order reaches a value equal to 0.84 . From this temperature on, the equivalent reaction order shows a reduction in increasing rate but gets more sensitive to the reactant concentration.

The impact of this behaviour on the soot depletion rate is represented in Figure 14(b). The results are normalised with respect to the soot depletion rate corresponding to $\mathrm{O}_{2}$ molar fraction equal to 0.08 and 1 bar in absolute pressure. The sensitivity of the soot depletion rate to variations in concentration can be divided into three different zones. As previously shown, the equivalent reaction order is assumed to be 0 below $350^{\circ} \mathrm{C}$ for any $\mathrm{O}_{2}$ molar fraction. Consequently, there is not impact on the normalised soot depletion rate till this temperature. Next, a transition zone is identified. From $350^{\circ} \mathrm{C}$ to $675^{\circ} \mathrm{C}$, the normalised soot depletion rate increases almost linearly. This zone is characterised by a gradual increasing difference in equivalent reaction order as the temperature rises for different $\mathrm{O}_{2}$ molar fractions. Nevertheless, unlike reaction order 1, a percentage increase in molar fraction does not lead to the same percentage increase in soot depletion rate, but to a smaller one. Therefore, the normalised soot depletion rate behaves as a system of reaction order $m$,

$$
\left.\tau_{s}\right|_{2} \sim \frac{\theta_{O_{2}}^{\prime}}{\theta_{O_{2}}}=\frac{\left(X_{O_{2}}^{\prime}\right)^{n^{\prime}}}{X_{O_{2}}^{n}}=\left(\frac{X_{O_{2}}^{\prime}}{X_{O_{2}}}\right)^{m},
$$

where $\tau_{s}$ is the normalised soot depletion rate, which in Eq. 20 is referred to zone 2, and $m$ is between 0 and 1.

The third zone is defined by a lowering of the increase in normalised soot depletion rate, which converges to an asymptotic value. Within this zone, the differences in reaction order as a function of the $\mathrm{O}_{2}$ molar fraction that appear 
as the temperature increases (Figure 14(a)) lead to a behaviour equivalent to a reaction order 1 system over $675^{\circ} \mathrm{C}$, i.e.:

$$
\left.\tau_{s}\right|_{3} \sim \frac{\theta_{O_{2}}^{\prime}}{\theta_{O_{2}}}=\frac{\left(X_{O_{2}}^{\prime}\right)^{n^{\prime}}}{X_{O_{2}}^{n}}=\frac{X_{O_{2}}^{\prime}}{X_{O_{2}}}
$$

During an active regeneration, the adsorption process causes spatial and time dependence on the equivalent $\mathrm{O}_{2}$ reaction order and, hence, on the soot depletion rate because of the substrate temperature and partial pressure fields. On the one hand, a thermal transient is undergone along the monolith. It defines the temperature field in the axial direction, as considered in 1D modelling. A tangential temperature gradient can be also found across the particulate layer thickness and the porous wall in high oxidation rate processes [75]. Additionally, a radial temperature field is found because of the heat transfer towards the environment [45]. On the other hand, the partial pressure field plays also a role because of the absolute pressure profile along the inlet channel [43] and the absolute pressure and concentration gradient across the porous medium. This field is in turn highly time dependent due to the pressure drop decrease during the regeneration.

With these boundaries, Figure 15 shows both the $\mathrm{O}_{2}$ surface coverage and equivalent reaction order throughout the modelled regenerations in Section 4.1. Taking into account that the inlet $\mathrm{O}_{2}$ molar fraction is constant, the results confirm the key role of the temperature being the absolute pressure smoothing covered up by the thermal transient. The $\mathrm{O}_{2}$ surface coverage only varies in the first half section of the monolith during the preheating stage. It gives as a result a front in equivalent reaction order, which is comparable to that in temperature. At this time, the equivalent reaction order is very homogenous in all the locations and close to its steady value. The temperature is higher in the case of initial soot mass equal to $22 \mathrm{~g} / 1$ (Figure 8). During the late oxidation stage the equivalent reaction order is around 0.8 , in comparison to 0.4 for the regeneration corresponding to $11 \mathrm{~g} / 1$ in initial soot mass. Finally, the late oxidation stage promotes a second transient phase in equivalent reaction order because of the heat released by the soot oxidation. At the end of this process, the convergence to the steady values of the $\mathrm{O}_{2}$ surface coverage and equivalent reaction order is reached. The comparison of the regeneration processes underlines the high sensitivity of the $\mathrm{O}_{2}$ equivalent reaction order to temperature but also the capability of the Langmuir isotherm to capture the impact of the reactants adsorption during different regeneration events.

\section{Summary and conclusions}

A 1D+1D soot oxidation model for wall-flow particulate filters has been presented in this work. The model is based on the solution of the governing equations in the inlet and outlet channels coupled to the gaseous reactants conservation equations across the particulate layer and the porous wall. The conservation equation of every gaseous reactant includes the definition of the reaction rate as a source term. It accounts for the internal pore diffusion of the gaseous reactants into the primary soot particles, the reactants adsorption onto the soot particle surface and the chemical kinetic step. 
As a first step, the capability of the proposed model has been assessed against active and passive regeneration tests. The overall soot depletion rate derivative during active regeneration events is useful to identify univocally three regeneration stages, i.e. preheating, maximum reactivity and late oxidation. These stages can be also determined from the pressure drop derivative, which is available experimentally and as an on-board parameter in real applications. Its use would result beneficial for an optimum calibration of on-board active regeneration and thermal management during the filter lifetime.

The inclusion of the internal pore diffusion and the adsorption steps in the reaction rate computation has been approached to account for internal and external soot oxidation. The limitations related to internal pore diffusion have been driven to correct the available internal soot specific surface. Its use allows capturing better the regeneration dynamics. In fact, to put the internal pore diffusion aside would lead to overestimate the temperature effect by means of a lower activation energy calibration.

The gaseous reactant adsorption has been modelled according to the Langmuir isotherm. The calculation of the surface coverage as a function of the temperature within a representative range of reactant concentration has revealed an equivalent $\mathrm{NO}_{2}$ reaction order in the range 0.3-0.4 in typical passive regeneration conditions. However, the $\mathrm{O}_{2}$ behaviour shows different regimes of reaction order. At temperature below the light-off, the equivalent $\mathrm{O}_{2}$ reaction order would be 0 . It starts growing up with temperature over $350^{\circ} \mathrm{C}$. If the temperature is below $675^{\circ} \mathrm{C}$, any change in $\mathrm{O}_{2}$ partial pressure has not relevant impact. Therefore, a change in molar fraction at constant temperature leads to a variation in soot depletion rate governed by a reaction order between 0 and 1 . The equivalent $\mathrm{O}_{2}$ reaction order continues increasing monotonously over $675^{\circ} \mathrm{C}$ but its value becomes dependent on the $\mathrm{O}_{2}$ partial pressure. As a consequence, a change in $\mathrm{O}_{2}$ concentration at constant temperature over $675^{\circ} \mathrm{C}$ leads to a soot depletion rate variation behaving like a reaction order 1 . The extrapolation of this response to wall-flow particulate filters gives as a result a field in equivalent $\mathrm{O}_{2}$ reaction order that mainly depends on the temperature field. Therefore, the $\mathrm{O}_{2}$ equivalent reaction order is dependent on time and space. Its value is determined by the dynamics of the thermal transient promoted by the engine to initiate the regeneration event and by the subsequent thermal transient governed by the soot oxidation rate.

\section{Acknowledgements}

This research has been partially supported by FEDER and the Government of Spain through project TRA201679185-R. Additionally, the Ph.D. student Enrique José Sanchis has been funded by a grant from Universitat Politècnica de València with reference FPI-2016-S2-1355.

\section{Appendix: Wall-flow particulate filter model}

The regeneration model is implemented into a fluid-dynamic solver for wall-flow particulate filters developed in previous works that is briefly described next. The PF model is a module of OpenWAM ${ }^{\mathrm{TM}}$, which is an open-source 
gas dynamics software for internal combustion engines and components computation developed at CMT-Motores Térmicos [76, 77]. The PF model solves the governing equations of mass, momentum and energy assuming nonhomoentropic one-dimensional unsteady compressible flow in a single pair of inlet and outlet channels. The flow field of these channels are coupled by the source terms related to the porous medium [43].

- Mass conservation

$$
\frac{\partial\left(\rho_{j} F_{j}\right)}{\partial t}+\frac{\partial\left(\rho_{j} u_{j} F_{j}\right)}{\partial x}=(-1)^{j} 4\left(\alpha-2 w_{p l}\right) \rho_{j} u_{w_{j}}
$$

- Momentum conservation

$$
\frac{\partial\left(\rho_{j} u_{j} F_{j}\right)}{\partial t}+\frac{\partial\left(\rho_{j} u_{j}^{2} F_{j}+p_{j} F_{j}\right)}{\partial x}-p_{j} \frac{d F_{j}}{d x}=-F_{w} \mu_{j} u_{j}
$$

- Energy conservation

$$
\frac{\partial\left(e_{0 j} \rho_{j} F_{j}\right)}{\partial t}+\frac{\partial\left(h_{0 j} \rho_{j} u_{j} F_{j}\right)}{\partial x}=q_{j} \rho_{j} F_{j}+(-1)^{j} 4\left(\alpha-2 w_{p l} j\right) h_{0 w} \rho_{j} u_{w j}
$$

- Chemical species conservation

$$
\frac{\partial\left(\rho_{j} Y_{k, j} F_{j}\right)}{\partial t}+\frac{\partial\left(\rho_{j} Y_{k, j} u_{j} F_{j}\right)}{\partial x}=(-1)^{j} 4\left(\alpha-2 w_{p l} j\right) \rho_{j} u_{w_{j}} Y_{k, w_{j}}
$$

In Eqs. (A.1)-(A.4), $j$ identifies the type of monolith channel $(0=$ outlet, $1=$ inlet $)$ and takes into account the existence of the particulate layer. The system of governing equations is solved applying finite difference methods and closed by the gas state equation in every channel. In particular, the two-step Lax\&Wendroff method [78] adapted to porous channels is applied coupled to a flux-corrected transport scheme [79]. In addition, the monolith channels are connected to inlet and outlet volumes that are included to account for the inertial pressure drop contribution because of flow expansion and diffusion. The volumes are solved by a filling and emptying method whilst the boundary conditions connecting 1D and 0D elements are solved applying the Method of Characteristics [80].

The regeneration model interacts with the solution of the conservation equations in different ways. Firstly, the soot oxidation defines the gas composition at the porous wall outlet, i.e. the mass fraction of every chemical species entering the outlet channel $\left(Y_{k, w_{0}}\right)$.

Secondly, the regeneration model takes part in the soot mass balance in every region of the porous medium. The amount of soot, both into the porous wall and in the particulate layer, determines a series of properties affecting the pressure drop, filtration and heat transfer processes. The solution of the PF model requires the calculation of the filtration velocity in the inlet channel. It is done as a function of the pressure difference between the inlet and the 
outlet channels, the cellular geometry and the permeability of every porous medium according to the Darcy's law applied at every axial node along the particulate layer and the porous wall [43]:

$$
u_{w_{\text {in }}}=\frac{p_{\text {in }}-p_{\text {out }}}{\frac{\mu_{\text {in }} w_{w}}{k_{w}} \frac{\rho_{\text {in }}\left(\alpha-2 w_{p l}\right)}{\rho_{\text {out }} \alpha}+\frac{\mu_{\text {in }}\left(\alpha-2 w_{p l}\right)}{2 k_{p l}} \ln \left(\frac{\alpha}{\alpha-2 w_{p l}}\right)}
$$

Known the filtration velocity in the inlet channel, then the one in the outlet channel is obtained considering the continuity equation across the porous medium:

$$
u_{w_{\text {out }}}=\frac{u_{w_{\text {in }}} \rho_{\text {in }}\left(\alpha-2 w_{p l}\right)}{\rho_{\text {out }} \alpha}
$$

The porous medium properties are dependent on the soot mass load, which varies the micro-geometry and the monolith meso-geometry because of the particulate layer thickness. Concerning the impact on the micro-geometry, the porous wall and particulate layer permeabilities applied in Eq. (A.5) are obtained assuming that both porous media behave as a packed bed of spherical particles [81]. Therefore, the permeability is obtained as a function of the porosity $(\varepsilon)$, the unit collector diameter $\left(d_{c}\right)$ and the slip-flow correction given by the Stokes-Cunningham factor (SCF) as [44]:

$$
k=f(\varepsilon) d_{c}^{2} S C F
$$

The diameter of the unit collector in the particulate layer is the mode of the particle size distribution; in the porous wall it is obtained taking into account the soot mass around a single collector $\left(m_{s_{\text {cell }}}\right)$ applying Equation (A.8)

$$
d_{c, w}=2\left(\frac{d_{c, w_{0}}^{3}}{8}+\frac{3 m_{s_{c e l l}}}{4 \pi \chi \rho_{s, w}}\right)^{\frac{1}{3}},
$$

where the apparent density of the collected soot is defined as the product of the density of soot aggregates of mean fractal dimension $\left(\rho_{s, w}\right)[60]$ and a shape factor $(\chi)$ representing the irregular deposition of the soot around the unit collector [44]. The variation of the unit collector diameter as the porous wall is loaded involves the porosity change. Known the unit cell diameter $\left(d_{c e l l, w}\right)$ from clean conditions,

$$
d_{c e l l, w}=\frac{d_{c, w_{0}}}{\left(1-\varepsilon_{w_{0}}\right)^{\frac{1}{3}}}
$$

the porous wall porosity under soot loading conditions is obtained as:

$$
\varepsilon_{w}=1-\frac{d_{c, w}^{3}}{d_{c e l l, w}^{3}} .
$$

The soot mass both in the porous wall and the particulate layer is determined every time-step accounting for the balance between filtrated and regenerated soot mass in every region. The filtration performance of the PF is governed by the fluid-dynamic field in the inlet channels and the microstructure [46]. In particular, the filtration efficiency is 
computed in an isolate unit collector accounting for Brownian diffusion, interception and inertial deposition mechanisms. The filtration efficiency of the porous wall is then obtained integrating within the packed bed control volume using the pore velocity as particle characteristic velocity [82],

$$
E_{f, w}=1-e^{-\frac{3 \eta_{D R I}\left(1-\varepsilon_{w}\right) w_{w} f_{s p} S_{c}}{2 \varepsilon_{w} d_{c, w}}}
$$

where $\eta_{D R I}$ is the overall filtration efficiency of an isolated unit collector.

Once the transition from deep bed to cake filtration regime is completed, the porous wall properties remain constant and the particulate layer acts as a barrier filter. Therefore, all the collected soot is assumed to be deposited on the particulate layer, which varies its thickness according to

$$
w_{p l}=\frac{\alpha-\sqrt{\alpha^{2}-\frac{m_{s, p l}}{\Delta x \rho_{s, p l}}}}{2},
$$

where $m_{s, p l}$ is the amount of soot in the particulate layer in the control volume of every axial node of the inlet channel.

Finally, the heat released by the soot oxidation also involves an impact on the heat transfer process. The rate of heat generated by the soot oxidation is included in the thermal balance solved in the porous medium of every control volume in which the channels are axially discretised:

$$
\rho c_{p} \frac{\partial T_{w}}{\partial t}=\left(\frac{\partial^{2} T_{w}}{\partial x^{2}}+\frac{\partial^{2} T_{w}}{\partial z^{2}}\right) \kappa+\dot{q}_{r e g}^{\prime \prime}
$$

In Eq A.13, $\dot{q}_{\text {reg }}^{\prime \prime}$ represents the heat released per unit of volume and time. A lumped nodal model is applied to solve the general heat transfer equation considering a bi-dimensional discretisation of the porous medium between a pair of inlet and outlet channels [45]. Besides the regeneration heat source, the model accounts for thermal inertia, gas to solid heat transfer, axial and tangential heat conduction across the porous medium and radial conduction towards the external canister, whose temperature is computed considering the heat losses to ambient.

\section{References}

[1] Badami M, Mallamo F, Millo F, Rossi EE, Influence of multiple injection strategies on emissions, combustion noise and BSFC of a DI common rail Diesel engine, SAE Technical Paper 2002-01-0503; 2002, doi:10.4271/2002-01-0503.

[2] Molina S, Guardiola C, Martín J, García-Sarmiento J, Development of a control oriented model to optimise fuel consumption and NO emissions in a DI Diesel engine, Appl Energ 2014;119:405-16.

[3] Maiboom A, Tauzia X, Hétet J, Experimental study of various effects of exhaust gas recirculation (EGR) on combustion and emissions of an automotive direct injection Diesel engine, Energy 2008;33:22-34.

[4] Johnson TV, Joshi A, Review of vehicle engine efficiency and emissions, SAE Technical Paper 2018-01-0329; 2018, doi:10.4271/2018-010329.

[5] Fino D, Diesel emission control: catalytic filters for particulate removal, Sci Technol Adv Mat 2007;8:93-100.

[6] Choi S, Oh K, Lee C, The effects of filter porosity and flow conditions on soot deposition/oxidation and pressure drop in particulate filters, Energy 2014;77:327-37. 
[7] Serrano JR, Bermúdez V, Piqueras P, Angiolini E, On the impact of DPF downsizing and cellular geometry on filtration efficiency in pre-and post-turbine placement, J Aerosol Sci 2017;113:20-35.

[8] Serrano JR, Climent H, Piqueras P, Angiolini E, Analysis of fluid-dynamic guidelines in diesel particulate filter sizing for fuel consumption reduction in post-turbo and pre-turbo placement, Appl Energ 2014;132:507-23.

[9] Lapuerta M, Rodríguez-Fernández J, Oliva F, Effect of soot accumulation in a diesel particle filter on the combustion process and gaseous emissions, Energy 2012;47:543-52.

[10] Tsuneyoshi K, Yamamoto K, A study on the cell structure and the performances of wall-flow diesel particulate filter, Energy 2012;48:492-9.

[11] Millo F, Andreata M, Rafigh M, Mercuri D, Pozzi C, Impact on vehicle fuel economy of the soot loading on diesel particulate filters made of different substrate materials, Energy 2015;86:19-30.

[12] Tsuneyoshi K, Yamamoto K, Experimental study of hexagonal and square diesel particulate filters under controlled and uncontrolled catalyzed regeneration, Energy 2013;60:325-32.

[13] Bensaid S, Caroca C, Russo N, Fino D, Detailed investigation of non-catalytic DPF regeneration, Can J Chem Eng 2011;89:401-7.

[14] Jiaqiang E, Zhao X, Xie L, Zhang B, Chen J, Zuo Q, et al., Performance enhancement of microwave assisted regeneration in a wall-flow diesel particulate filter based on field synergy theory, Energy 2019;169:719-29.

[15] Müller J, Frank B, Jentoft R, Schlögl R, Su D, The oxidation of soot particulate in the presence of NO 2 , Catal Today 2012;191:106-11.

[16] Jiaqiang E, Xie L, Zuo Q, Zhang G, Effect analysis on regeneration speed of continuous regeneration-diesel particulate filter based on $\mathrm{NO}_{2}$ assisted regeneration, Atmos Pollut Res 2016;7:9-17.

[17] Vlachos N, Patrianakos G, Kostoglou M, Konstandopoulos AG, Micro-simulation of NO- $\mathrm{NO}_{2}$ transport and reaction in the wall of a catalyzed diesel particulate filter, SAE Int J Fuels Lubr 2009;1:201-9.

[18] Wu X, Lin F, Xu H, Weng D, Effects of adsorbed and gaseous $\mathrm{NO}_{\mathrm{x}}$ species on catalytic oxidation of diesel soot with $\mathrm{MnO}_{\mathrm{x}}-\mathrm{CeO} \mathrm{O}_{2}$ mixed oxides, Appl Catal B-Environ 2010;96:101-9.

[19] Yamamoto K, Oohori S, Yamashita H, Daido S, Simulation on soot deposition and combustion in diesel particulate filter, Proc Combust Inst 2009;32:1965-72.

[20] Lapuerta M, Oliva F, Agudelo JR, Boehman AL, Effect of fuel on the soot nanostructure and consequences on loading and regeneration of diesel particulate filters, Combust Flame 2012;159:844-53.

[21] Bisset EJ, Mathematical model of the thermal regeneration of a wall-flow monolith diesel particulate filter, Chem Eng Sci 1984;39:1233-44.

[22] Shi YX, Cai YX, Li XH, Chen Y, Ding DW, Tang W, Mechanism and method of DPF regeneration by oxygen radical generated by NTP technology, Int J Automot Technol 2014;15:871-6.

[23] Koltsakis GC, Stamatelos AM, Modeling thermal regeneration of wall-flow diesel particulate filters. Reactors, kinetics and catalysis, AIChE J 1996;42:1662-72.

[24] Kandylas IP, Koltsakis GC, $\mathrm{NO}_{2}$-assisted regeneration of diesel particulate filters: a modeling study, Ind Eng Chem Res 2002;41:2115-23.

[25] Stanmore BR, Brilhac JF, Gilot P, The oxidation of soot: a review of experiments, mechanisms and models, Carbon 2001;39:2247-68.

[26] Kiyono M, Williams PJ, Koros WJ, Effect of pyrolysis atmosphere on separation performance of carbon molecular sieve membranes, J Membrane Sci, 2010;359:2-10.

[27] Smith IW, The combustion rate of coal chars: a review, Symp (Int) Combust 1982;19:1045-65.

[28] Kandas AW, Senel IG, Levendis Y, Sarofim AF, Soot surface area evolution during air oxidation as evaluated by small angle X-ray scattering and $\mathrm{CO}_{2}$ adsorption, Carbon 2005;43:241-51.

[29] Song J, Alam M, Boehman AL, Kim U, Examination of the oxidation behavior of biodiesel soot, Combust Flame 2006;146:589-604.

[30] Tighe CJ, Twigg MV, Hayhurst AN, Dennis JS, The kinetics of oxidation of diesel soots by NO 2 , Combust Flame 2012;159:77-90.

[31] Biggs MJ, Buts A, Virtual porous carbons: what they are and what they can be used for, Mol Simulat 2006;32:579-93.

[32] Singer SL, Ghoniem AF, Comprehensive gasification modeling of char particles with multi-modal pore structures, Combust Flame 2013;160:120-37.

[33] Hurt RH, Haynes BS, On the origin of power-law kinetics in carbon oxidation, Proc Combust Inst 2005;30:2161-8. 
[34] Ghiassi H, Toth P, Jaramillo IC, Lighty JS, Soot oxidation-induced fragmentation: Part 1: The relationship between soot nanostructure and oxidation-induced fragmentation, Combust Flame 2016;163:179-87.

[35] Guo H, Anderson PM, Sunderland PB, Optimized rate expressions for soot oxidation by $\mathrm{OH}$ and $\mathrm{O}_{2}$, Fuel 2016;172:248-52.

[36] Rodriguez-Fernandez J, Oliva F, Vazquez RA, Characterization of the diesel soot oxidation process through an optimized thermogravimetric method, Energy Fuels 2011;25:2039-48.

[37] Yezerets A, Currier NW, Kim DH, Eadler HA, Epling WS, Peden CHF, Differential kinetic analysis of diesel particulate matter (soot) oxidation by oxygen using a step-response technique, Appl Catal B-Environ 2005;61:120-9.

[38] Neeft JPA, Nijhuls TX, Smakman E, Makkee M, Moulijn J, Kinetics of the oxidation of diesel soot, Fuel 1997;76:1129-36.

[39] Wang H, Dlugogorski BZ, Kennedy EM, Coal oxidation at low temperatures: oxygen consumption, oxidation products, reaction mechanism and kinetic modelling, Prog Energ Combust 2003;29:487-513.

[40] Murphy JJ, Shaddix CR, Combustion kinetics of coal chars in oxygen-enriched environments, Combust Flame 2006;144:710-29.

[41] Essenhigh RH, Influence of initial particle density on the reaction mode of porous carbon particles, Combust Flame 1994;99:269-79.

[42] Messerer A, Niessner H, Pöschi U, Comprehensive kinetic characterization of the oxidation and gasification of model and real diesel soot by nitrogen oxides and oxygen under engine exhaust conditions: Measurement, Langmuir-Hinshelwood, and Arrhenius parameters, Carbon 2006;44:307-24.

[43] Torregrosa AJ, Serrano JR, Arnau FJ, Piqueras P, A fluid dynamic model for unsteady compressible flow in wall-flow diesel particulate filters, Energy 2011;36:671-84.

[44] Serrano JR, Arnau FJ, Piqueras P, García-Afonso O, Packed bed of spherical particles approach for pressure drop prediction in wall-flow DPFs (diesel particulate filters) under soot loading conditions, Energy 2013;58:644-54.

[45] Galindo J, Serrano JR, Piqueras P, García-Afonso O, Heat transfer modelling in honeycomb wall-flow diesel particulate filters, Energy 2012;43:201-13.

[46] Serrano JR, Climent H, Piqueras P, Angiolini E, Filtration modelling in wall-flow particulate filters of low soot penetration thickness, Energy 2016;112:883-98.

[47] Zeng T, Fu WB, The ratio $\mathrm{CO} / \mathrm{CO}_{2}$ of oxidation on a burning carbon surface, Combust Flame 1996;107:197-210.

[48] Jeguirim M, Tschamber V, Brilhac JF, Ehrburger P, Oxidation mechanism of carbon black by $\mathrm{NO}_{2}$ : effect of water vapour, Fuel 2005;84:194956.

[49] Haralampous OA, Koltsakis GC, Oxygen diffusion modeling in diesel particulate filter regeneration, AIChE J 2004;50:2008-19.

[50] Essenhigh RH, An integration path for the carbon-oxygen reaction with internal reaction, Symp (Int) Combust 1989;22:89-96.

[51] Essenhigh RH, Rate equations for the carbon-oxygen reaction: an evaluation of the Langmuir adsorption isotherm at atmospheric pressure, Energ Fuel 1991;5:41-6.

[52] Lee KJ, Han IH, Choi KH, Oxygen chemisorption on microporous carbons: an analysis of experimental data, Korean J Chem Eng 1995; 12:228-35.

[53] Kalberer M, Ammann M, Gäggeler HW, U. Baltensperger, Adsorption of $\mathrm{NO}_{2}$ on carbon aerosol particles in the low ppb range, Atmos Environ 1999;33:2815-22

[54] Jung H, Kittelson DB, Zachariah MR, Kinetics and visualization of soot oxidation using transmission electron microscopy, Combust Flame 2004;136:445-56.

[55] Ishiguro T, Suzuki N, Fujitani Y, Morimoto H, Microstructural changes of diesel soot during oxidation, Combust Flame 1991;85:1-6.

[56] Tighe CJ, Twigg MV, Hayhurst AN, Dennis JS, Adsorption and reaction of $\mathrm{NO}_{2}$ on carbon black and diesel soot at near-ambient temperatures, Ind Eng Chem Res 2011;50:10480-92.

[57] Jaramillo IC, Gaddam CK, Vander W, Randy L, Lighty JS, Effect of nanostructure, oxidative pressure and extent of oxidation on model carbon reactivity, Combust Flame 2015;162:1848-56.

[58] Lapuerta M, Rodríguez-Fernández J, Sánchez-Valdepeñas J, Salgado MS, Multi-technique analysis of soot reactivity from conventional and paraffinic diesel fuels, Flow Turbul Combust 2016;96:327-41. 
[59] Bermúdez V, Serrano JR, Piqueras P, Sanchis EJ, On the impact of particulate matter distribution on pressure drop of wall-flow particulate filters, Appl Sci 2017;7:234-55.

[60] Lapuerta M, Ballesteros R, Martos FJ, A method to determine the fractal dimension of diesel soot agglomerates, J Colloid Interface Sci 2006;303:149-58.

[61] Bisset EJ, Shadman F, Thermal regeneration of diesel-particulate monolithic filters, AIChE J 1985;31:753-8.

[62] Singh P, Thalagavara AM, Naber J, Johnson JH, Bagley ST, An experimental study of active regeneration of an advanced catalyzed particulate filter by diesel fuel injection upstream of an oxidation catalyst, SAE Technical Paper 2006-01-0879; 2006, doi:10.4271/2006-01-0879.

[63] Liati A, Eggenschwiler PD, Schreiber D, Zelenay V, Ammann M, Variations in diesel soot reactivity along the exhaust after-treatment system, based on the morphology and nanostructure of primary soot particles, Combust Flame 2013;160:671-81.

[64] Huo W, Zhou Z, Wang FN, Wang Y, Yu G, Experimental study of pore diffusion effect on char gasification with $\mathrm{CO}_{2}$ and steam, Fuel 2014;131:59-65.

[65] Hong J, Hecker WC, Fletcher TH, Improving the accuracy of predicting effectiveness factors for m-th order and Langmuir rate equations in spherical coordinates, Energ Fuel 2000;14:663-70.

[66] Salatino P, Zimbardi F, A fractal approach to the analysis of low temperature combustion rate of a coal char. II: Model development, Carbon $1994 ; 32: 51-9$

[67] Hill CG, An introduction to chemical engineering kinetics \& reactor design, New York: John Wiley \& Sons; 1977.

[68] Yang RT, Wong C, Kinetics and mechanism of oxidation of basal plane on graphite, J Chem Phys 1981;75:4471-6.

[69] Lahaye L, Ehrburger P, Fundamental issues in control of carbon gasification reactivity, Berlin/Heidelberg: Springer Science \& Business Media; 2012.

[70] Dubskỳ J, Beran S, Quantum chemical study of oxygen adsorption on graphite: II. Molecular orbital study of dissociation of molecular oxygen on graphite, Surf Sci 1979;79:53-62.

[71] Serrano JR, Bermudez V, Piqueras P, García-Afonso O, Pre-DPF water injection technique for loaded DPF pressure drop reduction and control, Appl Energ 2015;140:234-45.

[72] Desantes JM, Bermudez V, Molina S, Waldemar GL, Methodology for measuring exhaust aerosol size distributions using an engine test under transient operating conditions, Meas Sci Technol 2011;22:115101-15.

[73] Lújan JM, Bermudez V, Piqueras P, García-Afonso P, Experimental assessment of pre-turbo aftertreatment configurations in a single stage turbocharged Diesel engine. Part 1: Steady-state operation, Energy 2015;80:599-613.

[74] Payri F, Broatch A, Serrano JR, Piqueras P, Experimental-theoretical methodology for determination of inertial pressure drop distribution and pore structure properties in wall-flow diesel particulate filters (DPFs), Energy 2011;36:6731-44.

[75] Haralampous OA, Koltsakis GC, Intra-layer temperature gradients during regeneration of diesel particulate filters, Chem Eng Sci 2002;57:2345-55

[76] OpenWAM website, CMT-Motores Térmicos (Universitat Politécnica de Valéncia). 2018. www.openwam.org.

[77] Galindo J, Serrano JR, Arnau FJ, Piqueras P, Description of a semi-independent time discretization methodology for a one-dimensional gas dynamics model, J Eng Gas Turb Power 2009;131:034504/1-5.

[78] Lax PD, Wendroff B, Systems of conservation laws, Commun Pure Appl Math 1964;17:381-98.

[79] Serrano JR, Arnau FJ, Piqueras P, García-Afonso O, Application of the two-step Lax\&Wendroff-FCT and the CE-SE method to flow transport in wall-flow monoliths, Int J Comput Math 2014;91:71-84.

[80] Desantes JM, Serrano JR, Arnau FJ, Piqueras P, Derivation of the Method of Characteristics for the fluid dynamic solution of flow advection along porous wall channels, Appl Math Model 2012;36:3144-52.

[81] Konstandopoulos AG, Johnson JH, Wall-flow diesel particulate filters - Their pressure drop and collection efficiency, SAE Technical Paper 890405; 1989, doi:10.4271/890405.

[82] Logan BE, Jewett DG, Arnold RG, Bouwer EJ, O’Melia CR, Clarification of clean-bed filtration models, J Environ Eng 1995;121:869-73. 


\section{Nomenclature}




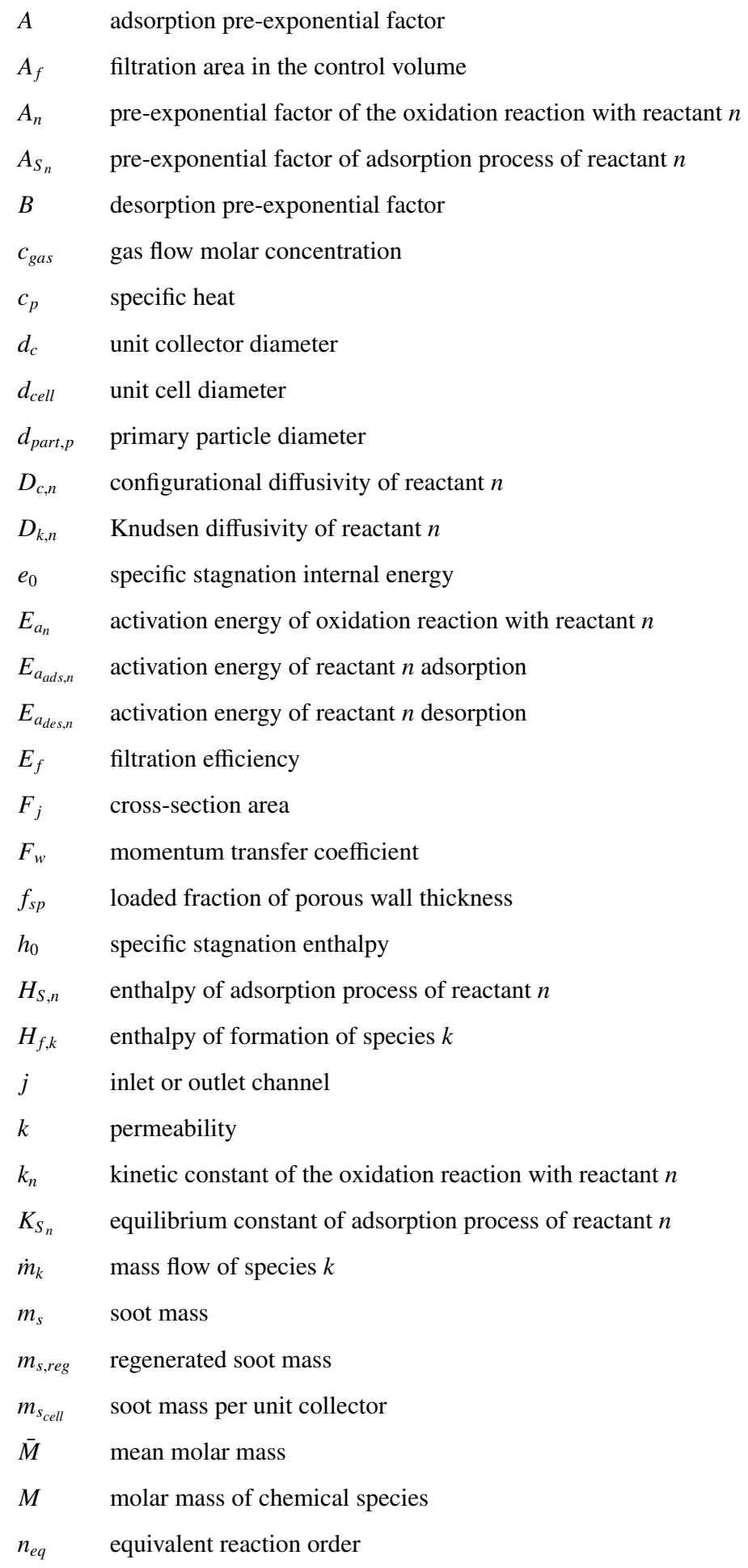




\begin{tabular}{ll}
$n_{n}$ & moles of reactant $n$ \\
$p$ & gas pressure \\
$p_{n}$ & partial pressure of reactant $n$ \\
$q$ & heat per unit of time and mass \\
$\dot{q}_{r e g}$ & power released by soot oxidation \\
$\dot{q}_{r e g, n}$ & power released by soot oxidation with reactant $n$ \\
$\dot{q}_{r e g}^{\prime \prime}$ & reaction power per unit of volume \\
$r_{p, s}$ & pore radius of soot primary particle \\
$\mathfrak{R}$ & universal gas constant \\
$S_{p}$ & soot specific surface \\
$S_{c}$ & sticking coefficient \\
$S C F$ & Stokes-Cunningham factor \\
$t$ & time \\
$T_{w}$ & substrate temperature \\
$u$ & gas velocity \\
$u_{w}$ & filtration velocity \\
$w$ & thickness \\
$x$ & axial dimension \\
$X$ & molar fraction \\
$Y$ & mass fraction \\
& tangential dimension \\
\hline &
\end{tabular}

Greek letters

$\begin{array}{ll}\alpha & \text { honeycomb cell size } \\ \alpha_{n} & \text { completeness index of reactant } n \\ \chi & \text { shape factor } \\ \Delta & \text { variation } \\ \Delta p_{D P F} & \text { DPF pressure drop } \\ \Delta x & \text { axial discretisation step } \\ \varepsilon & \text { porosity } \\ \phi_{n} & \text { Thiele modulus of reactant } n \\ \eta_{\text {int }} & \text { internal pore diffusion efficiency of reactant } n \\ \eta_{D R I} & \text { single unit collector efficiency } \\ \kappa & \text { thermal conductivity }\end{array}$




$\begin{array}{ll}\mu & \text { dynamic viscosity } \\ v & \text { stoichiometric coefficient } \\ \theta_{n} & \text { Langmuir isotherm of reactant } n \\ \rho & \text { density } \\ \tau_{s} & \text { normalised soot depletion rate } \\ \dot{\omega}_{n} & \text { reaction rate of reactant } n\end{array}$

Acronyms

OD zero-dimensional

1D one-dimensional

DPF diesel particulate filter

EATS exhaust gas aftertreatment system

F-TIR Fourier-Transform Infrared Spectroscoy

PF wall-flow particulate filter

SOF soluble organic fraction

SR-EGR short route exhaust gas recirculation

$\begin{array}{ll}\text { Subscripts } & \\ \text { ads } & \text { referred to adsorption } \\ \text { cell } & \text { referred to unit cell } \\ c & \text { referred to collector unit } \\ \text { des } & \text { referred to desorption } \\ \text { ext } & \text { referred to soot particle external properties } \\ \text { in } & \text { referred to inlet channel } \\ \text { int } & \text { referred to soot particle internal properties } \\ j & \text { referred to the type of monolith channel } \\ k & \text { referred to gaseous chemical species } \\ n & \text { referred to gaseous reactant } \\ \text { out } & \text { referred to outlet channel } \\ p & \text { referred to reaction product } \\ p l & \text { referred to particulate layer } \\ r e g & \text { referred to regeneration } \\ s & \text { referred to soot } \\ w & \text { referred to porous wall }\end{array}$




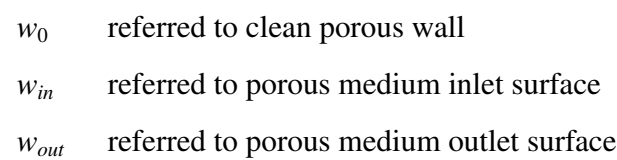

\section{List of Tables}

- Table 1. Parameters for the determination of the adsorption equilibrium constant of $\mathrm{O}_{2}$ and $\mathrm{NO}_{2}$.

- Table 2. Soot particles geometric properties.

- Table 3. DPF geometrical parameters.

- Table 4. Basic engine characteristics.

- Table 5. Soot oxidation kinetic parameters.

- Table 6. Kinetic parameters applied to analyse the effect of the internal pore diffusion on the regeneration dynamics.

\section{List of Figures}

- Figure 1. Scheme of the axial channels discretisation and the cross-section geometry of the inlet channel in a wall-flow particulate filter.

- Figure 2. Scheme of the limiting steps in the soot oxidation reaction.

- Figure 3. Adsorption activation energy as a function of the substrate temperature.

- Figure 4. Test cell scheme.

- Figure 5. Comparison of experimental data and modelling results: (a) DPF pressure drop and (b) gas temperature at the DPF outlet during active regeneration processes with initial soot mass of $22 \mathrm{~g} / 1$ and $11 \mathrm{~g} / 1$.

- Figure 6. Progress of (a) overall soot depletion rate and overall soot depletion rate derivative and (b) experimental and modelled pressure drop derivatives during active regeneration processes with initial soot mass of $22 \mathrm{~g} / 1$ and $11 \mathrm{~g} / 1$.

- Figure 7. Change in local flow and substrate properties along active regeneration processes with initial soot mass equal to $11 \mathrm{~g} / 1$ and $22 \mathrm{~g} / 1$.

- Figure 8. Progress of substrate temperature at different monolith locations during active regeneration processes with initial soot mass (a) $22 \mathrm{~g} / 1$ and (b) $11 \mathrm{~g} / 1$.

- Figure 9. Comparison between experimental and modelled DPF pressure drop during passive regeneration conditions: (a) soot mass dependence and (b) time dependence.

- Figure 10. Comparison between experimental and modelled molar concentration of NOx species at the DPF outlet during the soot loading test.

- Figure 11. Dependence of the internal pore diffusion efficiency of (a) $\mathrm{O}_{2}$ and (b) $\mathrm{NO}_{2}$ on the substrate temperature and the reactant concentration. 
- Figure 12. Impact of the internal pore diffusion efficiency in the modelling of an active regeneration event with $11 \mathrm{~g} / 1 \mathrm{in}$ initial soot mass.

- Figure 13. Surface concentration of (a) $\mathrm{O}_{2}$ and (b) $\mathrm{NO}_{2}$ as a function of the molar concentration and temperature at $p=1$ bar.

- Figure 14. Effect of temperature, absolute pressure and $\mathrm{O}_{2}$ molar fraction on (a) the equivalent reaction order and (b) the normalised soot depletion rate against $X_{O_{2}}=0.08$ and $p=1$ bar case.

- Figure 15. $\mathrm{O}_{2}$ surface coverage and equivalent reaction order along active regeneration processes with initial soot mass equal to (a) $22 \mathrm{~g} / 1$ and (b) $11 \mathrm{~g} / 1$.

Table 1: Parameters for the determination of the adsorption equilibrium constant of $\mathrm{O}_{2}$ and $\mathrm{NO}_{2}$.

\begin{tabular}{cccc}
\hline \hline$A_{S_{n}}[-]$ & $\mathrm{O}_{2}$ & $1 \times 10^{-4}$ & {$[51]$} \\
\cline { 2 - 4 } & $\mathrm{NO}_{2}$ & $5 \times 10^{-5}$ & {$[42]$} \\
\hline \multirow{2}{*}{$\Delta H_{S_{n}}[\mathrm{~J} / \mathrm{mol}]$} & $\mathrm{O}_{2}$ & $-7.7 \times 10^{4}$ & {$[52]$} \\
\cline { 2 - 4 } & $\mathrm{NO}_{2}$ & $-7.5 \times 10^{4}$ & {$[53]$} \\
\hline
\end{tabular}

\begin{tabular}{ccc}
\multicolumn{3}{c}{ Table 2: Soot particles geometric properties. } \\
\hline \hline$d_{p a r t, p}[\mathrm{~nm}]$ & 25 & {$[29,57,60]$} \\
$r_{p, s}[\mathrm{~nm}]$ & 0.4 & {$[25]$} \\
$S_{p, e x t, p l}\left[\mathrm{~m}^{-1}\right]$ & $6.72 \times 10^{7}$ & {$[28,59]$} \\
$S_{p, e x t, w}\left[\mathrm{~m}^{-1}\right]$ & $3.31 \times 10^{7}$ & {$[28,60]$} \\
$S_{p, \text { int }, p l}\left[\mathrm{~m}^{-1}\right]$ & $1.897 \times 10^{8}$ & {$[28,59]$} \\
$S_{p, \text { int }, w}\left[\mathrm{~m}^{-1}\right]$ & $9.349 \times 10^{7}$ & {$[28,60]$} \\
\hline \hline
\end{tabular}

\begin{tabular}{ll}
\multicolumn{2}{c}{ Table 3: DPF geometrical parameters. } \\
\hline \hline Diameter [mm] & 132 \\
Channel length [mm] & 200 \\
Cell density [cpsi] & 200 \\
Cell size [mm] & 1.486 \\
Porous wall thickness [mm] & 0.31 \\
Filtration area [m $\left.{ }^{2}\right]$ & 2.5 \\
Porosity [-] & 0.41 \\
Mean pore diameter $[\mu \mathrm{m}]$ & 12.1 \\
Permeability $\left[\times 10^{13} \mathrm{~m}^{2}\right]$ & 2.49 \\
\hline \hline
\end{tabular}


Table 4: Basic engine characteristics.

\begin{tabular}{ll}
\hline \hline Type of engine & HSDI Diesel \\
Emission standards & Euro 4 \\
Displacement & $1997 \mathrm{~cm}^{3}$ \\
Bore & $85 \mathrm{~mm}$ \\
Stroke & $88 \mathrm{~mm}$ \\
Number of cylinders & 4 in line \\
Number of valves & 4 per cylinder \\
Compression ratio & $18: 1$ \\
Maximum power @ speed & $100 \mathrm{~kW} @ 4000 \mathrm{rpm}$ \\
Maximum torque @ speed & $320 \mathrm{~kW} @ 1750 \mathrm{rpm}$ \\
\hline \hline
\end{tabular}

Table 5: Soot oxidation kinetic parameters.

\begin{tabular}{ccc}
\hline \hline$A_{n}[-]$ & $\mathrm{O}_{2}$ & 1.1 \\
\cline { 2 - 3 } & $\mathrm{NO}_{2}$ & 6 \\
\hline$E_{a_{n}}[\mathrm{~J} / \mathrm{mol}]$ & $\mathrm{O}_{2}$ & $1 \times 10^{5}$ \\
\cline { 2 - 3 } & $\mathrm{NO}_{2}$ & $9.5 \times 10^{4}$ \\
\hline \hline
\end{tabular}

Table 6: Kinetic parameters applied to analyse the effect of the internal pore diffusion on the regeneration dynamics.

\begin{tabular}{cccc}
\hline \hline & \multirow{2}{*}{ w/ diffusion } & \multicolumn{2}{c}{ w/o diffusion } \\
& & Setting A & Setting B \\
\hline$A_{O_{2}}[-]$ & 1.1 & 1.1 & 0.007 \\
$E_{a_{O_{2}}}[\mathrm{~J} / \mathrm{mol}]$ & $1 \times 10^{5}$ & $1 \times 10^{5}$ & $8.5 \times 10^{4}$ \\
\hline \hline
\end{tabular}




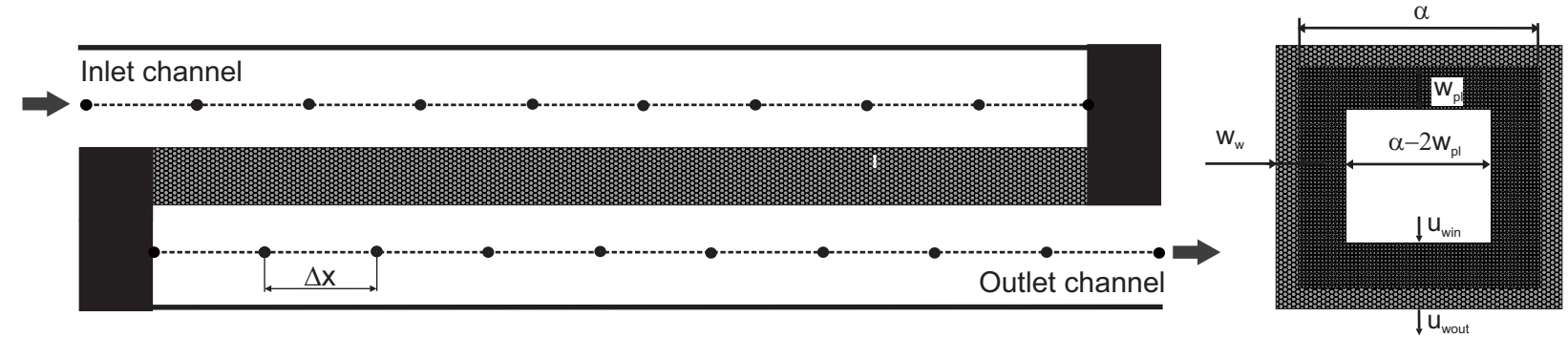

Figure 1: Scheme of the axial channels discretisation and the cross-section geometry of the inlet channel in a wall-flow particulate filter.

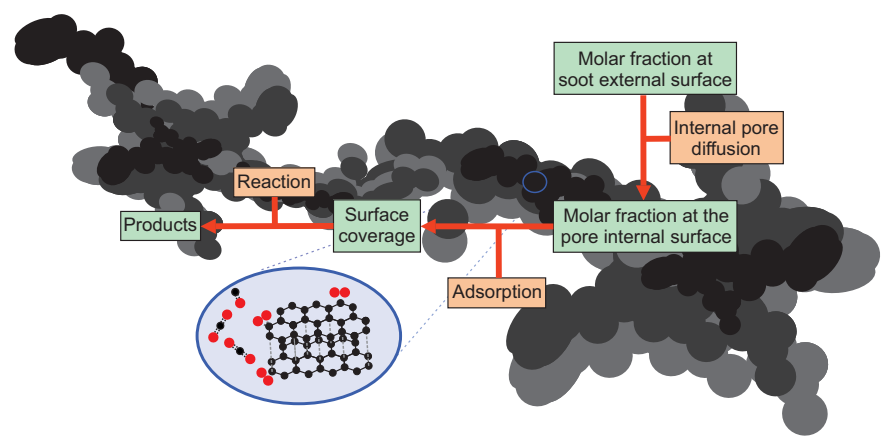

Figure 2: Scheme of the limiting steps in the soot oxidation reaction.

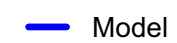

+ Salatino et al. [66]

- Yang and Wong [68]

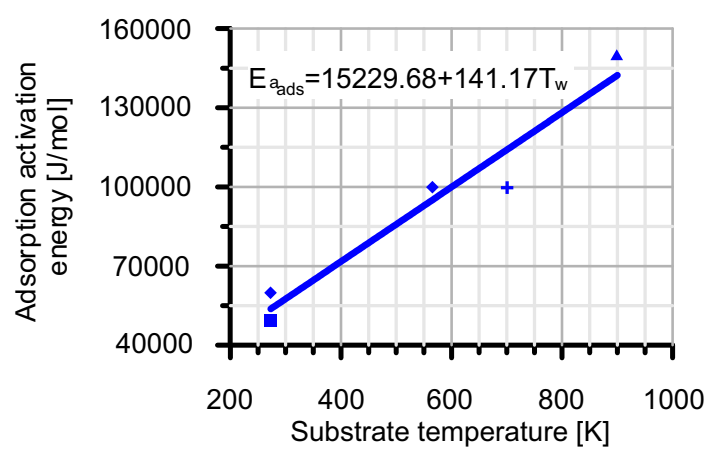

Figure 3: Adsorption activation energy as a function of the substrate temperature. 


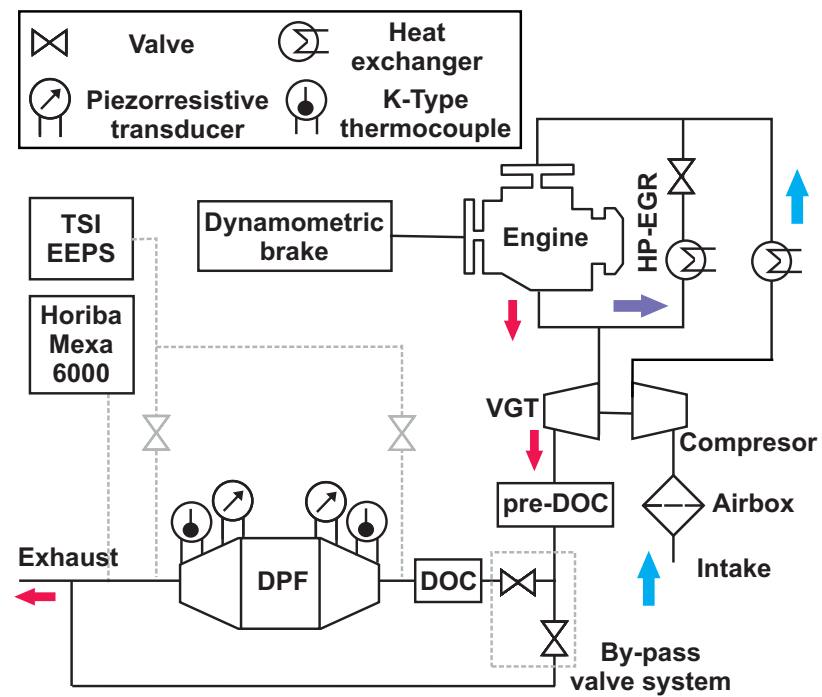

Figure 4: Test cell scheme.

\section{Experiment}

Model

Initial soot mass $22 \mathrm{~g} / \mathrm{l} \quad$ Initial soot mass $22 \mathrm{~g} / \mathrm{l}$
- Initial soot mass $11 \mathrm{~g} / \mathrm{l} \quad$ Initial soot mass $11 \mathrm{~g} / \mathrm{l}$

a)

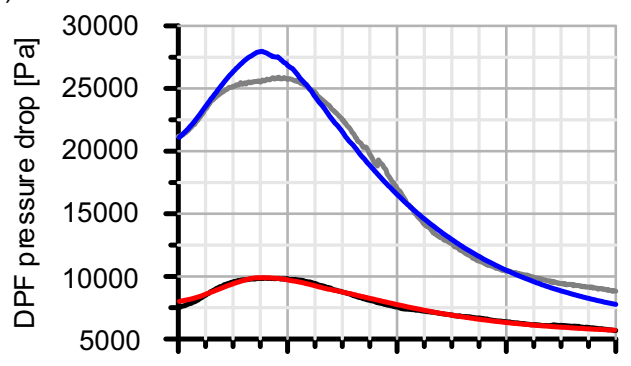

b)

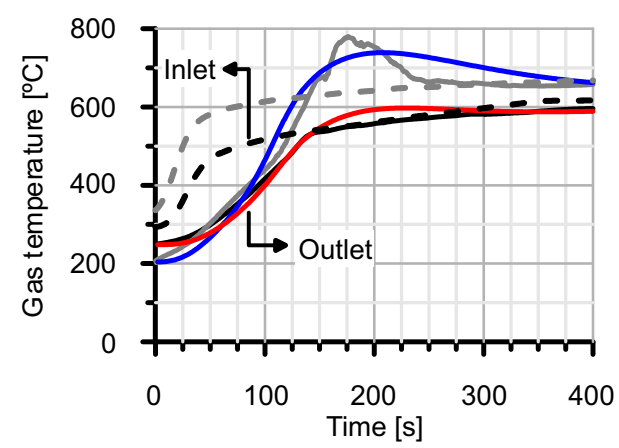

Figure 5: Comparison of experimental data and modelling results: (a) DPF pressure drop and (b) gas temperature at the DPF outlet during active regeneration processes with initial soot mass of $22 \mathrm{~g} / 1$ and $11 \mathrm{~g} / \mathrm{l}$. 


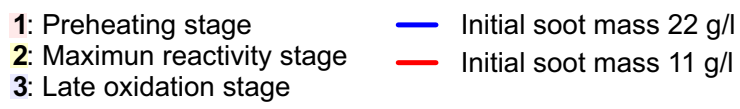

a)
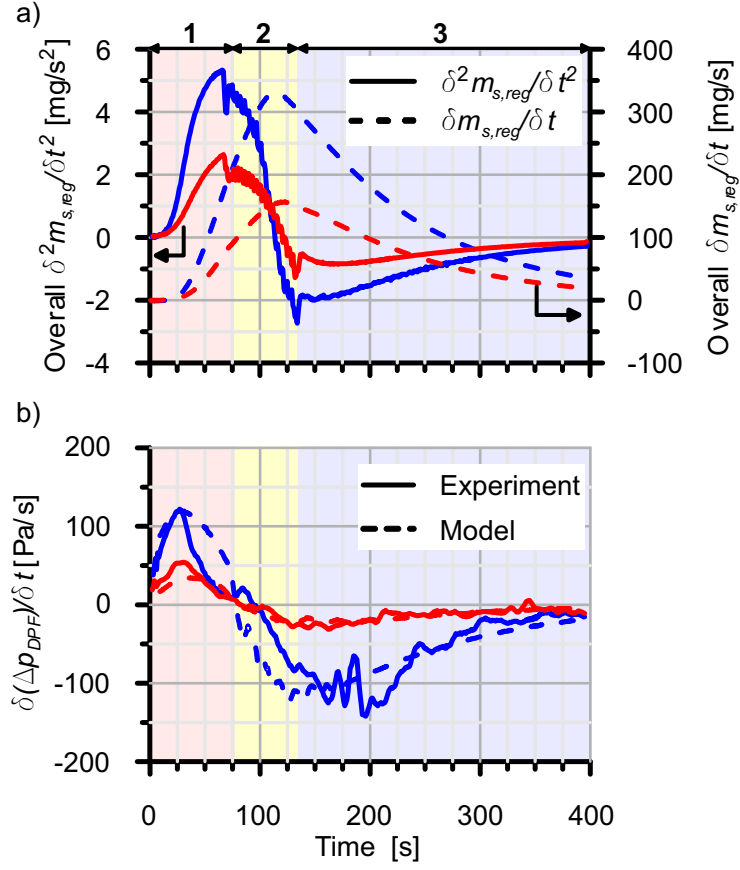

Figure 6: Progress of (a) overall soot depletion rate and overall soot depletion rate derivative and (b) experimental and modelled pressure drop derivatives during active regeneration processes with initial soot mass of $22 \mathrm{~g} / 1$ and $11 \mathrm{~g} / 1$. 


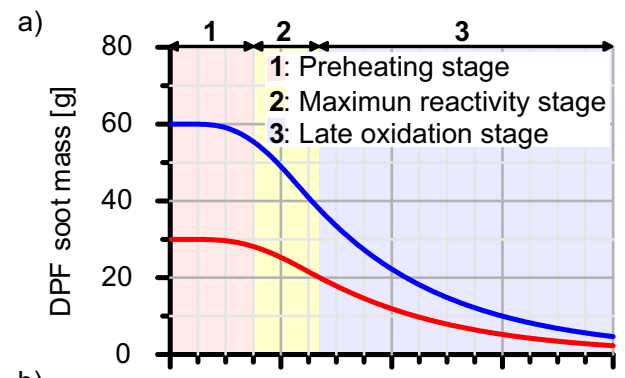

b)

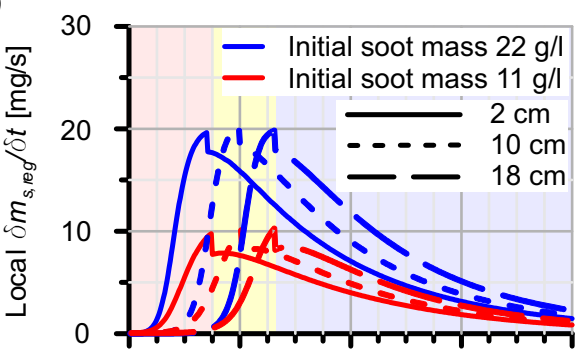

c)
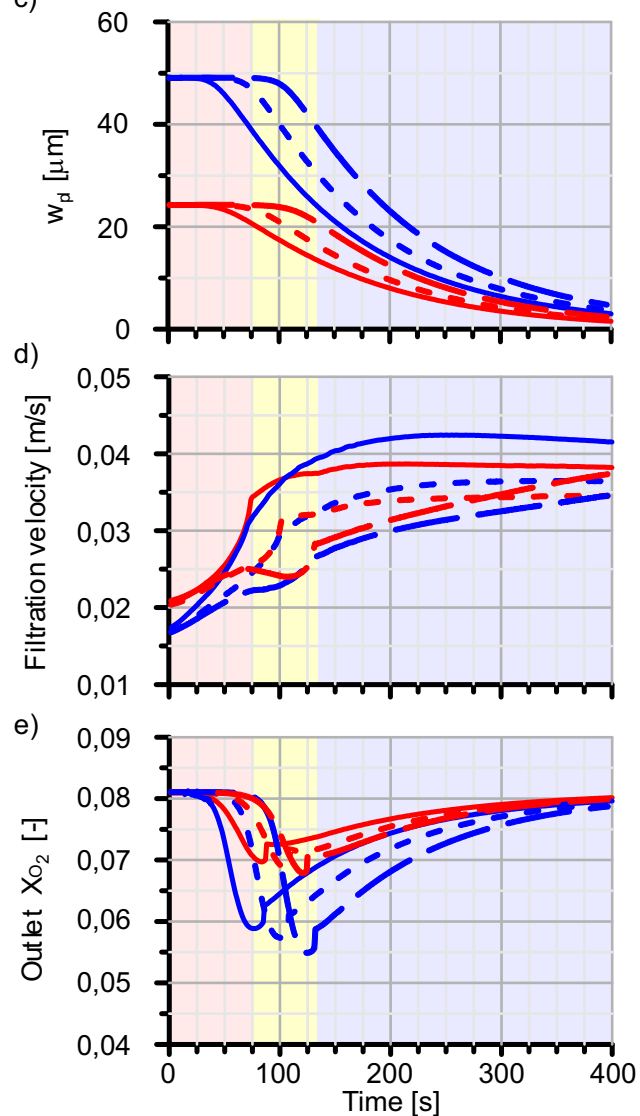

Figure 7: Change in local flow and substrate properties along active regeneration processes with initial soot mass equal to $11 \mathrm{~g} / 1 \mathrm{land} 22 \mathrm{~g} / \mathrm{l}$. 
a) Initial soot mass $22 \mathrm{~g} / \mathrm{l}$

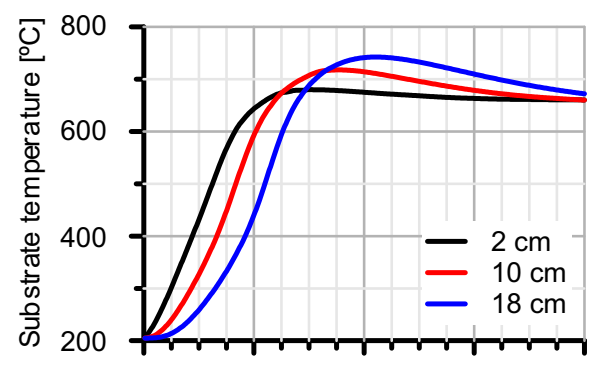

b) Initial soot mass $11 \mathrm{~g} / \mathrm{l}$

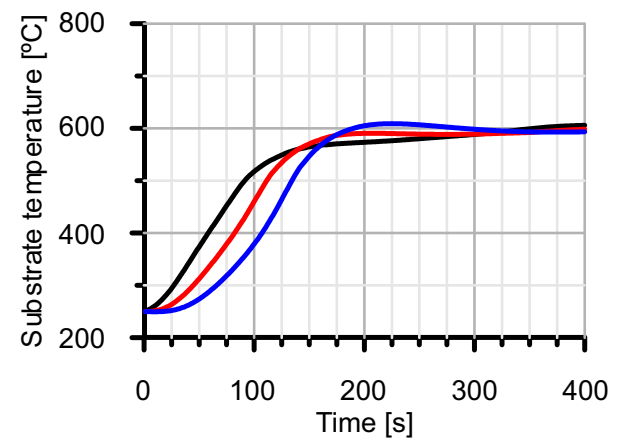

Figure 8: Progress of substrate temperature at different monolith locations during active regeneration processes with initial soot mass (a) $22 \mathrm{~g} / 1$ and (b) $11 \mathrm{~g} / 1$. 


$$
\text { - Experiment }-\begin{aligned}
& \text { Model } w / \\
& \text { regeneration }
\end{aligned}-\begin{aligned}
& \text { Model w/o } \\
& \text { regeneration }
\end{aligned}
$$

a)

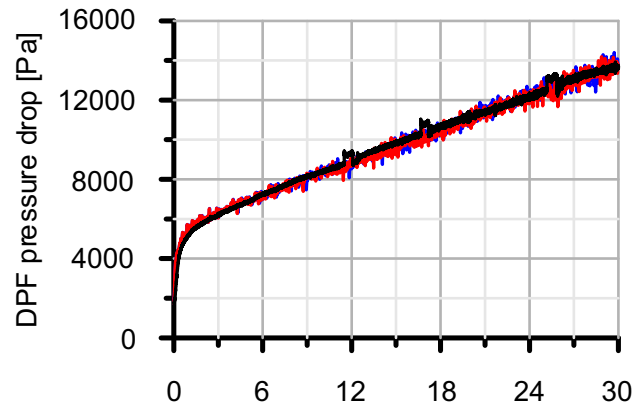

b)

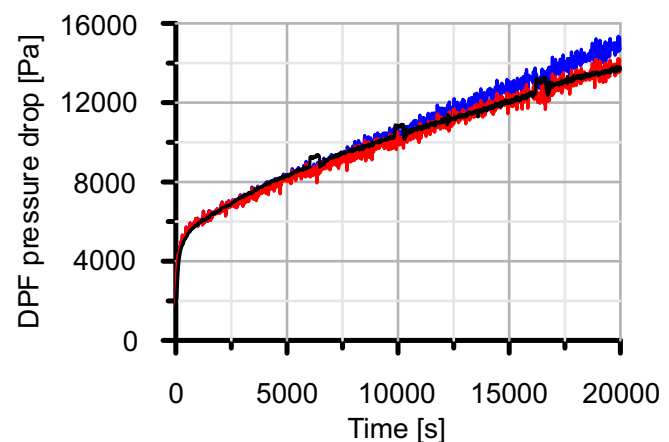

Figure 9: Comparison between experimental and modelled DPF pressure drop during passive regeneration conditions: (a) soot mass dependence and (b) time dependence.

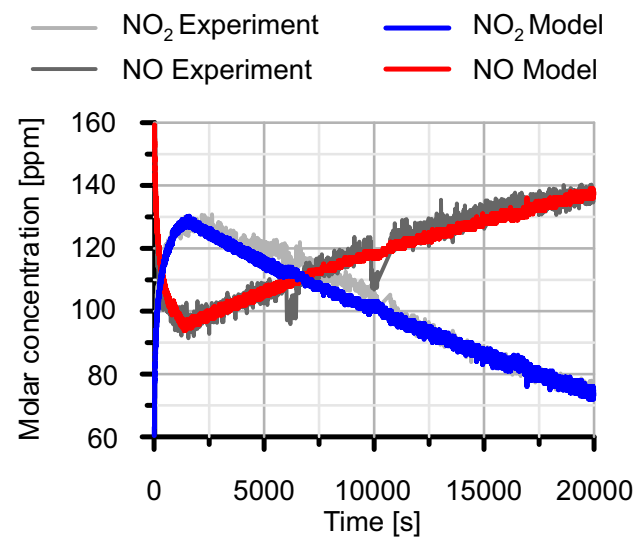

Figure 10: Comparison between experimental and modelled molar concentration of NOx species at the DPF outlet during the soot loading test. 


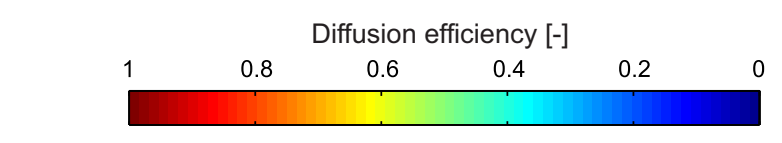

a) $\mathrm{O}_{2}$

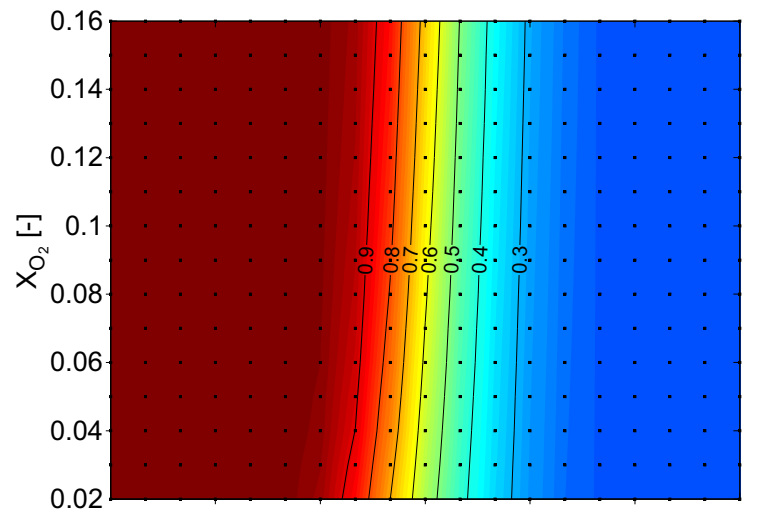

b) $\mathrm{NO}_{2}$

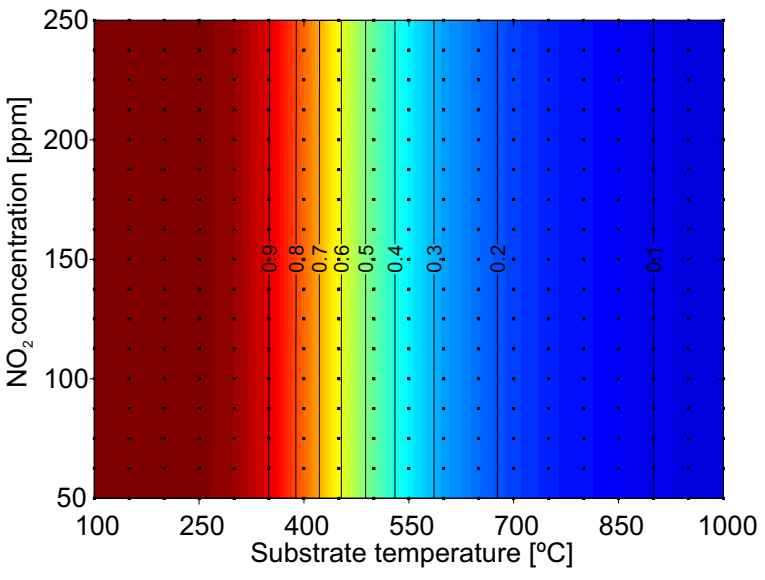

Figure 11: Dependence of the internal pore diffusion efficiency of (a) $\mathrm{O}_{2}$ and (b) $\mathrm{NO}_{2}$ on the substrate temperature and the reactant concentration. 
- Experimental

- Model w/ diffusion

a)

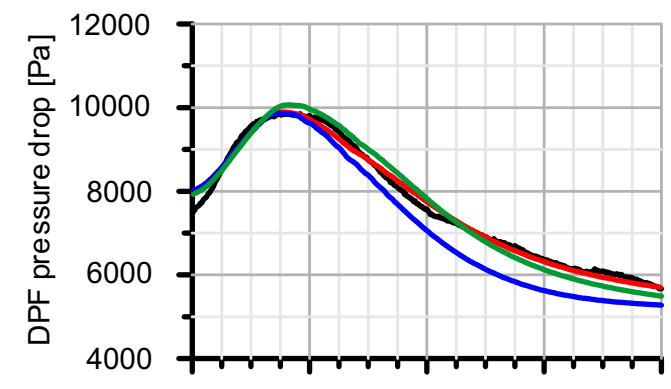

b)

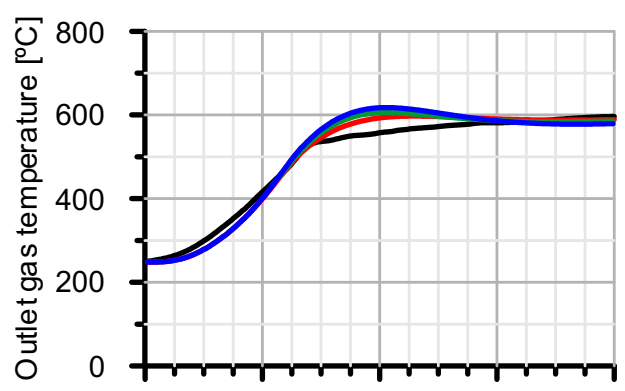

c)

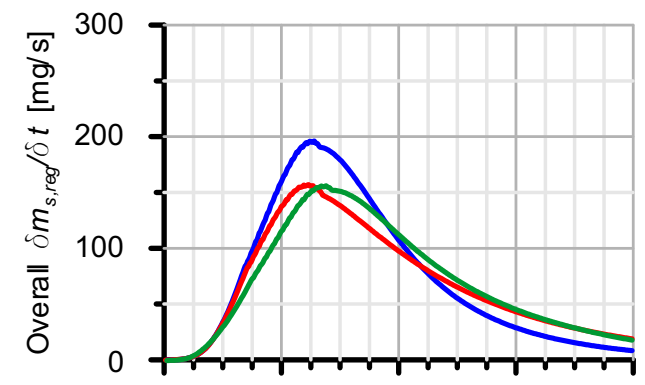

d)

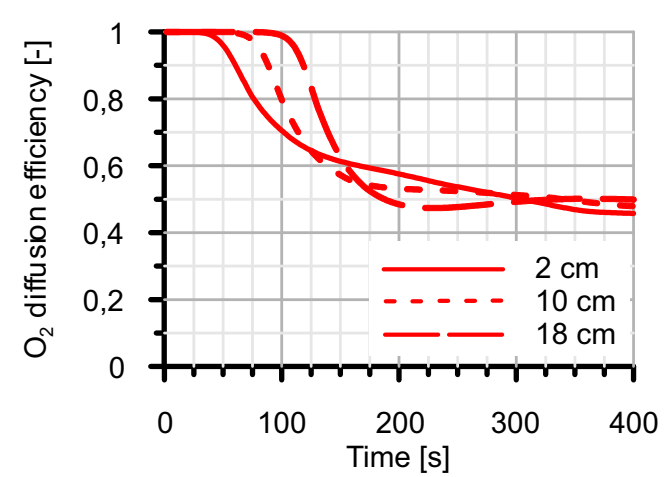

Figure 12: Impact of the internal pore diffusion efficiency in the modelling of an active regeneration event with $11 \mathrm{~g} / 1$ in initial soot mass. 

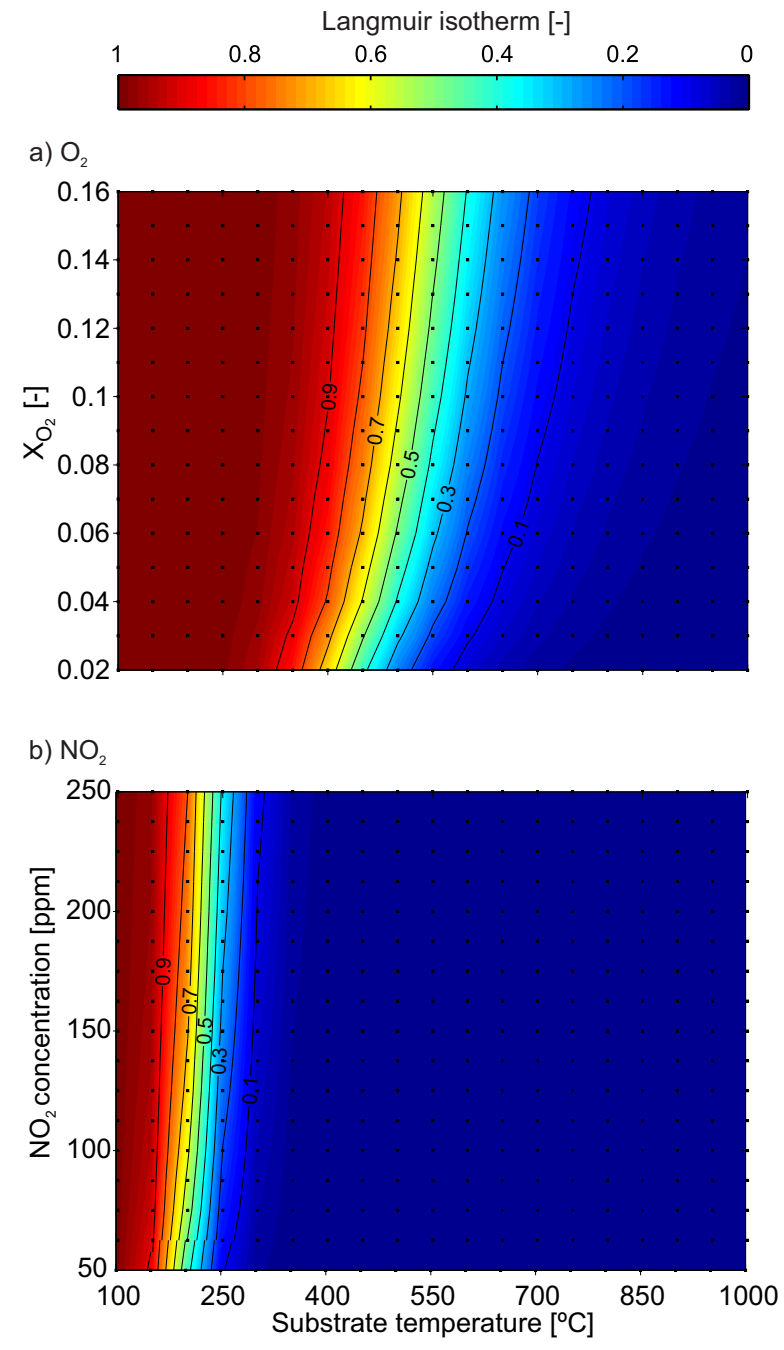

Figure 13: Surface concentration of (a) $\mathrm{O}_{2}$ and (b) $\mathrm{NO}_{2}$ as a function of the molar concentration and temperature at $p=1$ bar. 
a)

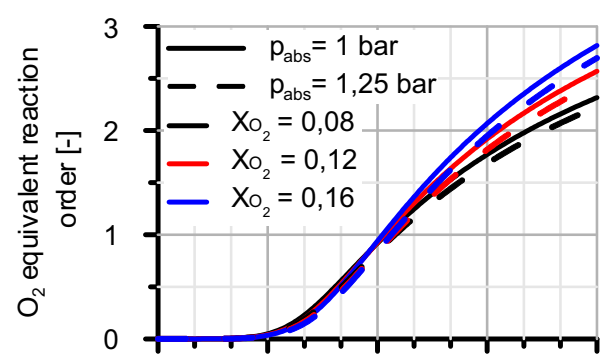

b)

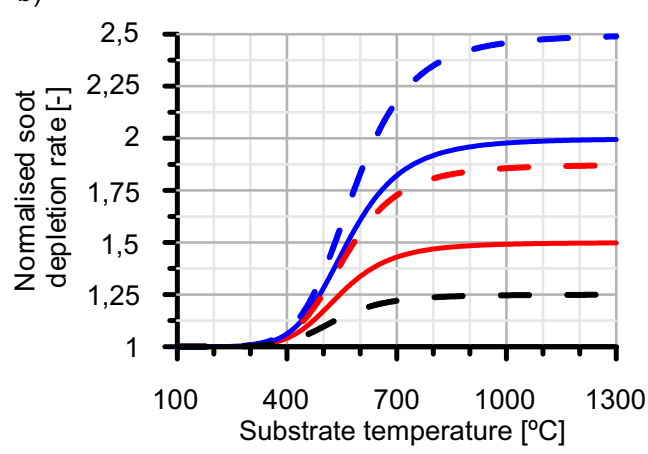

Figure 14: Effect of temperature, absolute pressure and $\mathrm{O}_{2}$ molar fraction on (a) the equivalent reaction order and (b) the normalised soot depletion rate against $X_{O_{2}}=0.08$ and $p=1$ bar case. 


$$
\begin{aligned}
& \text { 1: Preheating stage } \\
& \text { 2: Maximun reactivity stage } \\
& \text { 3: Late oxidation stage } \quad-10 \mathrm{~cm} \\
& \hline
\end{aligned}
$$

a) Initial soot mass $22 \mathrm{~g} / \mathrm{l}$

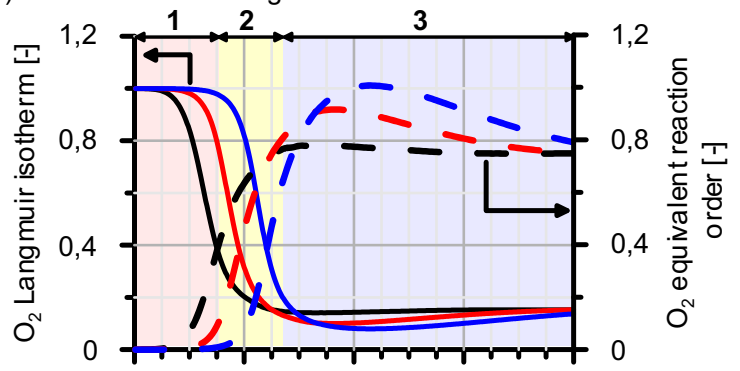

b) Initial soot mass $11 \mathrm{~g} / \mathrm{l}$

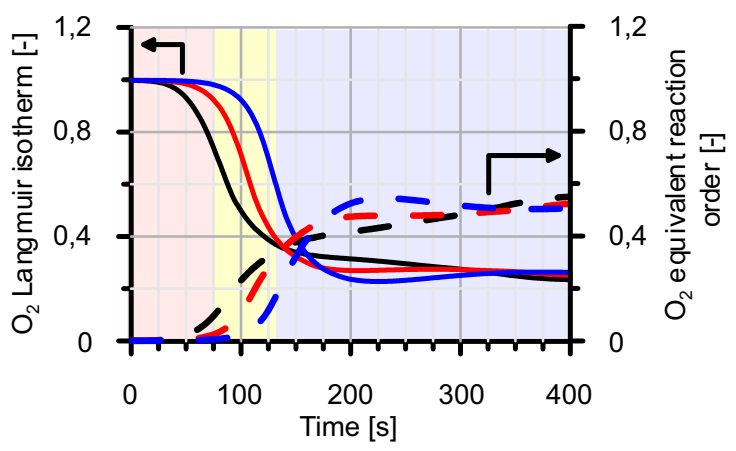

Figure 15: $\mathrm{O}_{2}$ surface coverage and equivalent reaction order along active regeneration processes with initial soot mass equal to (a) $22 \mathrm{~g} / \mathrm{l}$ and (b) $11 \mathrm{~g} / 1$ 